\title{
METODOLOGIAS DE ENSINO NA EDUCAÇÃO EM SEXUALIDADE: DESAFIOS PARA A FORMAÇÃO CONTÍNUA
}

\author{
METODOLOGÍAS DE ENSEÑANZA EN LA EDUCACIÓN EN SEXUALIDAD: RETOS \\ PARA LA FORMACIÓN CONTINUA
}

\author{
TEACHING METHODOLOGIES ON SEXUALITY EDUCATION: CHALLENGES FOR \\ IN-SERVICE TEACHER TRAINING
}

Teresa VILAÇA ${ }^{1}$

RESUMO: Nenhuma teoria ou modelo domina atualmente a investigação e prática na educação em sexualidade (ES) que, muitas vezes, é implementada sem qualquer referencial teórico. As diferentes metodologias de ensino aplicadas valorizam determinados constructos teóricos, usados de forma intencional, ou não, pelos/as professores/as quando recorrem a métodos e técnicas pedagógicos específicos. Assim, esta investigação visa compreender as práticas de professores/as para elaborar linhas orientadoras para a sua formação contínua em ES. Aplicouse uma entrevista semiestruturada a um/a professor/a de cada Agrupamento de Escolas, numa amostra aleatória representativa do Distrito de Braga, Portugal $(n=43)$. Observou-se que os temas/problemas abordados no ensino secundário, embora mais focados no pensamento crítico e na desconstrução de estereótipos relacionados com a sexualidade do que no $3^{\circ}$ ciclo, continuavam também a incluir essencialmente com a falta de conhecimento sobre saúde reprodutiva. Os principais métodos aplicados, baseados no construtivismo e na aprendizagem ativa, eram os métodos expositivo ativo e de discussão. O cruzamento dos temas e metodologia utilizados permitiu inferir que a maior parte dos professores/as não usava um referencial teórico explícito, mas valorizava constructos da Teoria Social Cognitiva e Modelo Ecológico. Estes resultados mostram que é importante na formação de professores/as: aprofundar o conhecimento sobre os diferentes temas/problemas interdisciplinares da sexualidade humana e os modelos teóricos; refletir sobre a prática para melhorar o conhecimento pedagógico do conteúdo.

PALAVRAS CHAVE: Educação em sexualidade. Modelos de educação para a saúde. Metodologias de ensino. Portugal.

RESUMEN: Ninguna teoría o modelo domina actualmente la investigación y práctica en la educación en sexualidad (ES) que, muchas veces, es implementada sin referencial teórico. Las distintas metodologías de enseñanza aplicadas valoran determinados constructos teóricos, utilizados de forma intencional, o no, por los/as profesores/as cuando recurren a métodos y técnicas pedagógicos específicos. Así, esta investigación visa comprender las prácticas de profesores/as para elaborar líneas orientadoras para su formación continua en ES. Se aplicó una entrevista semiestructurada a un/a profesor de cada Agrupamiento de Escuelas, en una

\footnotetext{
${ }^{1}$ Instituto de Educação da Universidade do Minho (IEUM), Braga - Portugal. Doutora em Educação - Área de Conhecimento de Metodologia do Ensino das Ciências. Centro de Investigação em Estudos da Criança (CIEC). ORCID: <http://orcid.org/0000-0002-5021-2613>. E-mail: tvilaca@ie.uminho.pt

RIAEE - Revista Ibero-Americana de Estudos em Educação, Araraquara, v. 14, n. 2, p. 1500-1537, jul., 2019. E-ISSN: $1982-5587$. 
amuestra aleatoria representativa del Distrito de Braga, Portugal ( $n=43)$. Se observó que los temas/problemas abordados en la enseñanza secundaria, aunque más enfocados en el pensamiento crítico y en la desconstrucción de estereotipos relacionados a la sexualidad que en el $3^{\circ}$ ciclo, seguían también incluyendo esencialmente con la falta de conocimiento sobre salud reproductiva. Los principales métodos aplicados, basados en el constructivismo y en el aprendizaje activo, eran los métodos expositivo activo y de discusión. El entrecruzamiento de los temas y metodología utilizados permitió inferir que gran parte de los profesores/as no utilizaban un referencial teórico explícito, pero valoraba constructos de la Teoría Social Cognitiva y Modelo Ecológico. Estos resultados mostraron que es importante en la formación del profesorado: profundizar el conocimiento sobre los distintos temas/problemas interdisciplinarios de la sexualidad humana y los modelos teóricos; reflexionar sobre la práctica para mejorar el conocimiento pedagógico del contenido.

PALABRAS CLAVE: Educación en sexualidad. Modelos de educación para la salud. Metodologías de enseñanza. Portugal.

ABSTRACT: Currently no theory or model dominates the research and practice in sexuality education (ES), which is often implemented without any theoretical background. The different teaching methodologies applied value specific theoretical constructs, used intentionally or not, by teachers when they resort to specific pedagogical methods and techniques. Thus, this research aims to understand the practices of teachers to develop guidelines for their in-service training on ES. A semi-structured interview was applied to a teacher from each School Network, in a random representative sample of the District of Braga, Portugal $(n=43)$. It was observed that the themes / problems addressed in secondary education, while more focused on critical thinking and the deconstruction of stereotypes related to sexuality than in the third cycle, also continued to be mainly included the lack of knowledge about reproductive health. The main methods applied, based on constructivism and active learning were the active lecturing and discussion methods. The triangulation of the themes and methodology used allowed us to infer that most of the teachers did not use an explicit theoretical framework but valued constructs of the Cognitive Social Theory and Ecological Model. These results show that it is important in teacher training: to deepen knowledge about the different interdisciplinary themes / problems of human sexuality and theoretical models; to reflect on the practice to improve pedagogical content knowledge.

KEYWORDS: Sexuality education. Health education models. Teaching methodologies; Portugal.

\section{Introdução}

As escolas estão a ser relativamente bem-sucedidas na organização e criação de métodos e técnicas para que os alunos e alunas construam grandes corpos de conhecimento conceitual e factual. No entanto, as práticas pedagógicas mais frequentes, apesar de centradas nos alunos e alunas, dão pouca atenção aos métodos que os/as envolvem em experiências reais ou simuladas que lhes permitem usar o conhecimento adquirido na realização de tarefas complexas 
relacionadas com a vida real. Além disso, quando esses métodos são utilizados, a ênfase é muitas vezes colocada no uso de estratégias estandardizadas para a resolução de problemas apresentados pelo professor ou professora, que envolvem apenas subcompetências de baixo nível desenvolvidas em relativo isolamento (VILAÇA, 2008).

Poucos recursos são dedicados a atividades de resolução de problemas de ordem superior que exigem que os alunos e alunas integrem e (re)construam e/ou apliquem conhecimento conceitual e desenvolvam adequadamente subcompetências de resolução de problemas. Como resultado, para uma grande parte de alunos e alunas os conhecimentos conceituais e as competências para resolver problemas adquiridos na escola não são suficientes ou permanecem não integrados, impossibilitando-os/as de contribuir para a resolução de problemas societais, dito por outras palavras, para agirem como cidadãos ativos e participativos em sociedades democráticas (VILAÇA, 2014). Em alguns casos, o conhecimento e as subcompetências de resolução de problemas permanecem vinculados aos problemas apresentados na sala de aula de forma estandardizada, através de situações simuladas como no role-playing e nos estudos de caso, em vez de estarem vinculados ao seu conhecimento de estratégias de resolução de problemas ou à sua competência para investigarem as caraterísticas intrínsecas aos problemas em si, que lhes permitem vir a resolvê-los (VILAÇA; JENSEN, 2014). Isto significa, que os problemas que caem fora desses padrões simulados em sala de aula, pela sua novidade, por um lado, não invocam as estratégias adequadas de resolução de problemas e o conhecimento conceitual relevante para o resolver. Por outro lado, os alunos e alunas não conseguem usar os recursos disponíveis para melhorar as suas competências de resolução de problemas, porque lhes faltam as técnicas necessárias para o fazer.

Ultrapassar esta lacuna exige passar de modelos de educação para a saúde e sexualidade orientados para as mudanças de comportamento individuais (ex., Modelo de Crenças de Saúde, Teoria da Ação Racional e Comportamento Planeado, Modelo Transteórico) e interpessoais (ex. Teoria Social Cognitiva) para modelos de aprendizagem orientados para a resolução de problemas reais que envolvem a mudança de estilos de vida e condições de vida (aprendizagem baseada em projetos orientados para a resolução de problemas reais). A educação para a saúde e sexualidade também está preocupada com as abordagens para resolver problemas sociais, por outras palavras, em provocar mudanças. Neste âmbito tem sido feito um esforço considerável de investigadores/as e práticos/as para desenvolverem técnicas que alterem os comportamentos que não são promotores de saúde e bem-estar individual e comunitário. Por um lado, as técnicas que "empurram" as pessoas para mudar foram experimentadas por muitos como manipuladoras, 
reduzindo a liberdade de escolha e sustentando um equilíbrio de poder a favor do "agente da mudança", por outro lado, ocorreu uma mudança de paradigma, e a maioria das técnicas comportamentais de hoje (por exemplo, de promoção do apoio social, capacitação e crescimento pessoal) baseiam-se na redução de obstáculos à mudança e na promoção da tomada de decisões informadas, em vez de pressionar as pessoas para mudarem (GLANZ; RIMER; VISWANATH, 2008). Num momento em que os modelos ecológicos começam a ser mais claramente articulados e estudados, novos paradigmas para a compreensão, o estudo e a aplicação do conhecimento sobre o comportamento humano continuam a surgir e são influentes nas ciências sociais aplicadas aos comportamentos de saúde e educação para a saúde, estando as intervenções sobre fatores sociais e comportamentais vinculadas a múltiplos níveis de influência, em vez de apenas se concentrarem num número único ou limitado de determinantes da saúde. Dentro desta perspectiva atual surge o paradigma de educação para a saúde democrática, operacionalizado com o modelo pedagógico IVAM (Investigação, Visão, Ação e Mudança) que tem sido aplicado na educação em sexualidade por Vilaça e colaboradores (VILAÇA, 2017).

Em síntese, para promover diferenças reais no desenvolvimento das competências dos alunos e alunas para resolverem problemas relacionados com a sexualidade e género de si próprios e a da comunidade, é preciso compreender as práticas dos professores e professoras para elaborar métodos adequados de formação contínua de professores e professoras que visem a promoção do seu desenvolvimento profissional e pessoal no contexto em que ensinam a educação em sexualidade. Assim, o estudo teve como objetivos: i) identificar os temas/problemas trabalhados nos últimos três anos na educação em sexualidade; ii) caracterizar os métodos e técnicas utilizadas na educação em sexualidade.

\section{Referencial teórico}

\section{Modelos e teorias mais usados em educação para a saúde e sexualidade}

A educação em sexualidade como parte integrante da promoção e educação para a saúde nas escolas usa os seus modelos e teorias. Hoje, nenhuma teoria ou estrutura conceitual domina a pesquisa ou prática nesta área, havendo uma multiplicidade de teorias. No entanto, uma revisão de literatura realizada em 1990 mostrou que as três teorias mais frequentemente mencionadas eram o Modelo de Crenças de Saúde, a Teoria da Ação Racional e a Teoria da Aprendizagem Social (GLANZ; LEWIS; RIMER, 2002) e, outra revisão de literatura realizada 
entre 2000 e 2005, mostrou que eram o Modelo de Crenças de Saúde (Health Belief Model), o Modelo Transteórico/Fases de Mudança (The Transtheoretical Model/ Stages of Change) e a Teoria Social Cognitiva (Social Cognitive Theory) (GLANZ; RIMER; VISWANATH, 2008). Neste sentido, optamos por rever estas teorias para analisar se elas, ou alguns dos seus constructos, foram usados pelos professores e professoras entrevistados/as na educação em sexualidade realizada nos últimos três anos. Os modelos ecológicos e o modelo IVAM também foram revistos pelo seu valor prático na educação para a saúde e, mais especificamente, na educação em sexualidade em Portugal.

Modelo de crenças de saúde (The Health Belief Model). Este modelo foi desenvolvido para compreender a forma como o indivíduo percebe o mundo e como essas percepções motivam o seu comportamento (BREWER; RIMER, 2008). Neste modelo explicitam-se quatro componentes essenciais e duas adicionadas posteriormente (motivação para agir e autoeficácia) para explicar porque é que o indivíduo tem potencialidades para mudar um comportamento particular (FREIMUTH, 1992; KIRSCHT; JOSEPH, 1989): 1) susceptibilidade pessoal para condições de saúde negativas (ex. gravidez não planeada, infeção pelo VIH); 2) percepção da severidade da condição; 3) valor do comportamento (benefícios, eficácia); 4) barreiras para a ação; 5) motivação para agir; 6) autoeficácia. De acordo com Kirscht e Joseph (1989), a 'susceptibilidade' é a probabilidade de se ter a condição de saúde negativa na ausência de ações específicas e a 'severidade da condição' é relativa a todas as desvantagens significativas vistas na ameaça de saúde. Na sua perspectiva, a combinação das duas constitui a percepção da ameaça pessoal. Freimuth (1992) explica que ‘o valor do comportamento' é avaliado pela estima dos potenciais benefícios para manter os comportamentos de saúde recomendados para redução da suscetibilidade ou severidade, pesados contra a percepção dos custos físicos, psicológicos e outras barreiras inerentes aos comportamentos de saúde recomendados.

Modelo Transteórico e Fases de Mudança (The Transtheoretical Model). O Modelo Transteórico (TTM) parte de muitos outros modelos orientados para o comportamento de saúde do indivíduo, concentrando-se mais nas mudanças de comportamento e menos nas variáveis cognitivas (como o risco percebido ou barreiras percebidas), porque se acredita que é a fase da mudança de comportamento em que se encontra que prediz o comportamento de saúde e a mudança de comportamento (GLANZ; LEWIS; RIMER, 2002). Esta teoria argumenta que as pessoas estão em diferentes estágios de prontidão para fazer mudanças no comportamento de saúde, e essas fases são qualitativamente diferentes em relação às construções e processos que aproximam as pessoas do comportamento, logo, as pessoas devem receber intervenções 
apropriadas para a sua fase no processo de mudança de comportamento (BREWER; RIMER, 2008; GLANZ; LEWIS; RIMER, 2002). O pressuposto fundamental subjacente é semelhante ao princípio básico da educação para a saúde de 'começar onde as pessoas estão', pois, uma vez que a fase de mudança é avaliada, devem ser proporcionadas às pessoas intervenções orientadas por terapeutas, autoiniciadas ou outras adequadas às suas necessidades (BREWER; RIMER, 2008). As fases de mudança do modelo transteórico são as seguintes (GLANZ; LEWIS; RIMER, 2002): 1) pré-contemplação: não tem intenção de agir dentro dos próximos 6 meses; 2) contemplação: tem intenção de agir dentro dos próximos 6 meses; 3) preparação: tem intenção de agir dentro dos próximos 30 dias e tem realizado alguns passos comportamentais nessa direção no último ano; tem um plano de ação (ex. juntar-se a uma aula de educação em sexualidade, consultar um conselheiro, falar com médico); 4) ação: tem mudado comportamentos notoriamente pelo menos durante seis meses; nem todas as modificações de comportamento contam como ações; só são ações se os cientistas e os profissionais concordam que é suficiente para reduzir o risco de doença; 5) manutenção: tem mudado comportamentos notoriamente por mais de seis meses; as pessoas trabalham para prevenir a recaída, mas não aplicam os processos de mudança tão frequentemente como as pessoas em ação; têm menos tentação de recaída e aumentam a autoconfiança de que podem continuar as mudanças; 6) conclusão: esta fase é aplicada a alguns comportamentos, especialmente às adições; nesta fase o indivíduo não tem tentativas e tem 100\% de autoeficácia; ele tem a certeza que nenhuma situação de depressão, ansiedade, aborrecimento, solidão, zanga ou stress o fará voltar aos velhos hábitos não saudáveis, como uma maneira para lidar com essas situações.

Teoria Social Cognitiva e Autoeficácia (The Social Cognitive Theory). Esta teoria, conhecida inicialmente como Teoria da Aprendizagem Social por estar baseada na operacionalização dos princípios de aprendizagem estabelecidos no contexto social humano, foi renomeada Teoria Social Cognitiva por ter passado a integrar conceitos da psicologia cognitiva para explicar as capacidades de processamento de informações humanas e os vieses que influenciam a aprendizagem a partir da experiência, observação e comunicação simbólica, e por ter adotado, posteriormente, conceitos de sociologia e ciência política para compreender as capacidades de funcionamento e adaptativas dos grupos e sociedades, e conceitos da psicologia humanística, para analisar os processos subjacentes à autodeterminação, altruísmo e comportamento moral (MCALISTER; PERRY; PARCEL, 2008). Esta teoria enfatiza o determinismo recíproco na interação entre as pessoas e seus ambientes e postula que o 
comportamento humano é o produto da interação dinâmica de influências pessoais, comportamentais e ambientais (BANDURA, 1997). Os constructos desta teoria são os seguintes (MCALISTER; PERRY; PARCEL, 2008): i) determinismo recíproco, isto é, os fatores ambientais influenciam indivíduos e grupos, mas os indivíduos e grupos também podem influenciar os seus ambientes e regular os seus próprios comportamentos (ex., planificar o acesso fácil aos serviços de saúde, melhora os comportamentos de proteção em relação à gravidez não planeada e ISTs); ii) expectativas dos resultados, ou seja, as crenças sobre a probabilidade e o valor das consequências das escolhas comportamentais (ex., mudar as expectativas sobre o prazer associado ao uso do preservativo); iii) autoeficácia, ou seja, as crenças sobre a habilidade pessoal para realizar comportamentos que tragam os resultados desejados (ex. melhorar a crença da mulher sobre a sua habilidade para convencer o parceiro a usar preservativo); iv) eficácia coletiva, que corresponde às crenças sobre a habilidade do grupo para realizar ações concertadas que tragam os resultados desejados (ex., organização de conferencias para pais/ mães pelos alunos e alunas para melhorar o diálogo sobre sexualidade em casa); v) aprendizagem por observação, isto é, aprender a realizar novos comportamentos por exposição a exibições interpessoais ou representações nos média dessas exibições, particularmente através da modelagem de pares (ex., observação de telenovelas); vi) incentivo à motivação, isto é, o uso e mau uso de recompensas e punições para modificar o comportamento (ex., as leis de punição do assédio sexual podem desencorajar os assediadores e encorajar as vítimas a denunciar; v) facilitação, ou seja, fornecer ferramentas, recursos ou mudanças ambientais que tornem mais fácil realizar comportamentos novos (ex., distribuir gratuitamente preservativos); vi) autorregulação, isto é, controlar-se a si próprio/a através da automonitorização, definição de metas, feedback, autorrecompensa, autoinstrução e pedido de ajuda nas redes de suporte social; vii) descomprometimento moral, isto é, formas de pensar sobre os comportamentos nocivos e as pessoas prejudicadas que tornam a inflação de sofrimento aceitável, desvinculando-se dos padrões morais de autorregulação (ex., a naturalização da discriminação de género influencia a sua reprodução na sociedade).

Modelos ecológicos. Weare (1998) descreveu a abordagem eco-holística da promoção da saúde na escola (Figura 1). 
Figura 1 - Modelo Eco-Holístico da Escola Promotora de Saúde

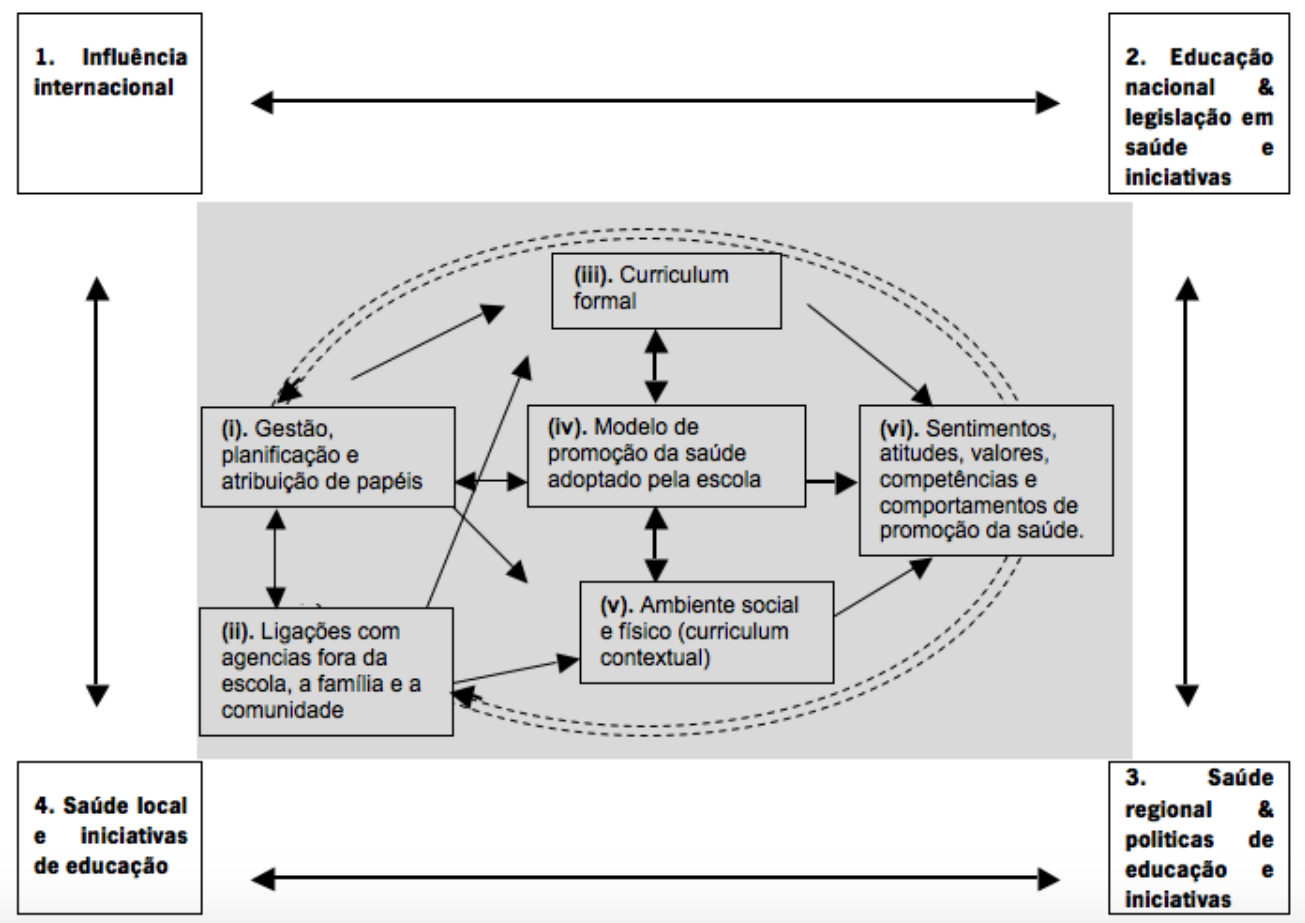

Fonte: Weare (1998); Parsons, Stears e Thomas (2002).

Desde 1980 a Organização Mundial de Saúde tem-se focado na necessidade de "suporte social e ambientes naturais" muitas vezes sumariados como abordagens de lugares saudáveis (healthy settings). O Modelo Eco-holístico da Escola Promotora de Saúde foca-se no desenvolvimento de ambientes saudáveis, onde, para as pessoas, as escolhas saudáveis são as escolhas mais fáceis e também as mais racionais. De acordo com Parsons, Stears e Thomas (2002), este modelo salienta e demonstra a existência de fatores que influenciam a estrutura e o desenvolvimento das escolas como lugares promotores da saúde, mostrando que alguns desses fatores são externos à escola e outros são gerados internamente. Na sua perspectiva as áreas de influência externas à escola formam uma organização estrutural útil para investigar, medir e avaliar a promoção da saúde. Por exemplo, no contexto das escolas na Europa, os fatores externos (1-4) podem ser: influências internacionais tais como o conceito de escola promotora de saúde mantido pela Rede de Escolas para a Saúde na Europa (SHE); legislação nacional sobre sexo e orientação da educação para a saúde nas escolas; políticas de educação e iniciativas sobre saúde reprodutiva regional e segurança; e campanhas de saúde locais e programas educativos. Os fatores internos principais (i-vi) são a distribuição de papéis dentro da escola, tal como um coordenador da promoção e educação para a saúde; ligações com a comunidade 
envolvente, por exemplo, ligações casa - escola com os professores, governadores e associação de pais; curriculum de educação para a saúde e sexualidade formal e contextual, por outras palavras, o que é ensinado e aprendido na sala de aula e as mensagens de saúde positivas ou negativas são exemplificadas pelas práticas e comportamentos na escola; o modelo ou abordagem adoptado para a promoção da saúde na escola, por exemplo, uma abordagem de mudança de comportamento, de autocapacitação ou de mudança social; e os resultados, tais como sentimentos, atitudes, valores, competências e comportamentos de saúde positivos dos alunos e alunas e staff. Segundo Weare (1998), este modelo reconhece que a saúde é o produto de uma miríade de fatores físicos, sociais e psicológicos inter-relacionados e interatuando entre eles. A premissa básica da perspectiva ecológica é que fornecer aos indivíduos motivação e habilidades para mudar o comportamento pode não ser eficaz se os ambientes e as políticas tornarem difícil ou impossível escolher comportamentos saudáveis, por isso, devemos criar ambientes e políticas que tornem conveniente, atraente e económico fazer escolhas saudáveis e, em seguida, motivar e educar as pessoas sobre essas escolhas (SALLIS; OWEN; FISHER, 2008).

Paradigma de educação para a saúde democrática e modelo pedagógico IVAM na educação em sexualidade. Atualmente, como já há quase vinte anos atrás, há uma grande liberdade formal de acesso ao consumo de informação sobre sexualidade, modificaram-se as leis mais restritivas que proibiam a contracepção, perseguiam determinadas condutas (e.g. homossexualidade) e impediam o divórcio, e dá-se mais liberdade aos/às jovens, embora, em muitos casos seja entendida como algo que se permite mas não como um direito (LÓPEZ; FUERTES, 1999). Neste contexto, surgiu o modelo de educação em sexualidade, designado por Sánchez $(1999,2002)$ como modelo profissional ou aberto, que assume uma postura mais relativista, baseada em conhecimentos científicos e em atitudes democráticas, tolerantes e abertas, com o objetivo de favorecer a aceitação positiva da própria identidade sexual e a aprendizagem de conhecimentos que permitam viver as diferentes possibilidades da sexualidade em cada idade, conforme a pessoa ou pessoas implicadas o desejem. Este modelo está enquadrado no Paradigma de Educação para a Saúde Democrática, criado algum tempo antes por Jensen (1997) no âmbito das escolas promotoras de saúde. Dentro deste paradigma, a aprendizagem baseada em projetos (ABPj) orientados para ação de promoção da saúde sexual, trabalha um conhecimento interdisciplinar, não somente em relação às consequências de problemas de saúde sexual, mas também, de suas causas, visões em relação ao problema no futuro e o conhecimento em relação a estratégias para encontrar soluções para esse problema 
(VILAÇA; JENSEN, 2014; VILAÇA, 2017). O modelo IVAM (Investigação, Visão Ação e Mudança) foi desenvolvido para usar nas escolas para estruturar projetos de investigação e ação que promovem a participação do aluno e aluna, com o objetivo de construir o seu próprio conhecimento orientado para ação e desenvolver ações (JENSEN, 2000; SIMOVSKA; JENSEN, 2003; VILAÇA; JENSEN, 2010). No ensino orientado para a ação, o objetivo é que os alunos e alunas, com todos os meios disponíveis, possam mudar o seu comportamento numa direção previamente determinada por eles/as próprios/as (JENSEN; SCHNACK, 1994). Essa é a componente mais profunda do conceito de ação e que o torna diferente do conceito de mudança de comportamento (JENSEN, 1994; SIMOVSKA; JENSEN, 2003). Antes de uma ação, tem que haver uma tomada de decisão consciente, o que é uma dimensão democrática muito importante na educação para a saúde (JENSEN, 1994) e, mais especificamente, na educação em sexualidade democrática (VILAÇA, 2014; VILAÇA; JENSEN, 2014), que não é necessário no caso da mudança de comportamento. A mudança de comportamento poderá ser causada pela pressão de outra pessoa (ex., o/a professor/a ou colegas) ou por outras circunstâncias como a publicidade, estando a pessoa a seguir só as tendências (orientações) recebidas sem estar consciente das suas ações.

\section{Métodos e técnicas em educação para a saúde e sexualidade}

Uma definição tecnicista, estandardizada, sobre o que são métodos, técnicas e estratégias de ensino não é relevante para o processo de ensino. Na verdade, esta é uma sistematização tipificada do trabalho docente, que pode recorrer a outras sistematizações na sua planificação para atender às novas formas de ensinar e ao contexto e caraterísticas dos alunos e alunas. No entanto, atendendo a que esta é uma categorização frequente para descrever as práticas de ensino, nomeadamente na aplicação das teorias e modelos de educação para a saúde e sexualidade, estes conceitos serão sinteticamente clarificados e, posteriormente, aplicados na análise dos resultados obtidos na investigação das práticas dos professores e professoras em educação em sexualidade. A etimologia da palavra 'método' encontra-se no latim 'methodus', que por sua vez se origina no grego 'meta' que significa meta ou objetivo, e 'thodos' que significa percurso ou meios para o alcançar. Assim, o método é o percurso ou meio para se chegar a um ou a vários objetivos, isto é, são as técnicas e estratégias utilizadas pelo professor ou professora, muitas vezes sem orientações teóricas definidas (JOYCE; WEIL, 1996). A palavra 'técnica' etimologicamente vem do grego 'technicu' e do latim 'technicus', é o processo 
de como fazer algo, como realizá-lo. Assim, o método é o percurso e a técnica é como fazê-lo, logo, a metodologia de ensino é o conjunto de métodos, técnicas e estratégias de ensino. A escolha da metodologia de ensino é feita de acordo com a teoria de ensino que adoptamos. Dentro da metodologia de ensino, a escolha dos métodos depende de fatores lógicos, biopsicológicos, epistemológicos, didáticos, socioeconómicos, históricos e culturais e as técnicas para processar os métodos recebem muita influência dos fatores do contexto. Podemos distinguir essencialmente quatro tipo de métodos: expositivo, discussão, investigação e experiencial.

Método expositivo. É útil para ensinar informação a um grande grupo, especialmente quando é necessário apresentar uma grande quantidade de conhecimento. Silberman (2006) argumentam que se estamos comprometidos com uma aprendizagem ativa este método enfrenta um potencial problema: a exposição coloca os participantes numa posição prolongada de ouvintes e a aprendizagem não pode ocorrer simplesmente ouvindo e vendo, pois é necessário que ocorra um processamento mental da pessoa para que a aprendizagem aconteça. No entanto, o método expositivo pode ter um lugar importante num programa de formação ativo se forem utilizadas técnicas participativas para: construir o interesse dos participantes; maximizar a compreensão e retenção da informação; envolver os participantes durante a exposição e, quando a exposição estiver completa, reforçá-la (SILBERMAN; LAWSON, 1995; SILBERMAN, 2006).

Métodos de discussão. Incluem uma variedade de técnicas para uma troca de ideias aberta e colaborativa entre um professor ou professora e os seus alunos e alunas, ou entre alunos/as, com o objetivo de promover a organização do pensamento, a aprendizagem, a resolução de problemas e a compreensão dos conteúdos (BROOKFIELD; PRESKILL, 2005). Geralmente, envolvem a discussão de um problema ou tópico que tenha na sua base um texto escrito, um filme (ou qualquer material media) ou uma norma social, como acontece frequentemente na educação em sexualidade (VILAÇA, 2017). Outro termo para discussões utilizadas para fins pedagógicos são conversas pedagógicas (THARP; GALLIMORE, 1988). Uma característica determinante da discussão é que os alunos e alunas têm um envolvimento considerável na construção de conhecimento, compreensão ou interpretação, por outras palavras, eles/as têm uma "autoridade interpretativa" considerável para avaliar a plausibilidade ou a validade das respostas (para maior aprofundamento ver SVINIVKI; MCKEACHIE et al., 2011). Em qualquer método de discussão, os/as participantes apresentam múltiplos pontos de vista, respondem às ideias dos outros e refletem sobre as suas próprias ideias num esforço para 
construir o seu conhecimento e compreender ou interpretar o assunto em questão. Podem ocorrer discussões entre membros de uma díade, grupo pequeno ou classe inteira e ser conduzidos por professores ou professoras ou por alunos e alunas. As "histórias " ou "cenários" dos estudos de caso estimulam a discussão (HILTON, 2001), pois são construídas a partir das histórias da vida real que desencadeiam uma conversa em que as pessoas aprendem sobre sexo, comportamento sexual e prazer sexual, exercitam a sua compaixão e comiseração (ex., com as vítimas de abuso sexual) e satisfazem a sua curiosidade sobre o que os outros fazem e sobre como se "faz", uma vez que retratam histórias públicas e privadas contadas em conversas no dia-a-dia (CASH; KHAN; NASREEN; BHUIYA; CHOWDHURY; CHOWDHURY, 2001).

Métodos de investigação. Estes métodos envolvem os alunos e alunas na aprendizagem ativa para explorar um tópico ou problema específico. As investigações podem estar relacionadas com a aprendizagem baseada em inquérito, às vezes usada como forma sinónima de investigação. Normalmente considera-se a aprendizagem baseada em inquérito mais aberta, envolvendo raciocínio de ordem superior e um diálogo de um nível mais alto em contextos de trabalho em grupo (BISHOP et al., 2004). Nas investigações (ex., experiencias laboratoriais para investigar a reação dos espermatozoides ao calor), essas discussões em grupo podem ser mais dirigidas pelo professor ou professora do que entre alunos/as. A aprendizagem baseada em inquérito é um processo centrado no aluno ou aluna e dirigido por ele/a. O objetivo é envolvê-lo/a na aprendizagem ativa e ser idealmente baseada nas suas próprias questões de investigação. Este método socioconstrutivista, baseia-se amplamente em ideias Vygotskianas (VYGOTSKY, 2000), pois o desenvolvimento e a aprendizagem devem combinar o que um aluno ou aluna pode fazer sozinho e sob orientação de adultos ou colegas mais experientes, enfatizando a importância da cooperação dentro da qual encontra e usa ferramentas ou recursos produzidos pelos parceiros de pesquisa. Neste método os alunos e alunas seguem de perto o método científico, pois fazem observações (e encontram problemas sobre o que não entendem), formulam questões, analisam livros e outras fontes de informação para ver o que já é conhecido, planificam investigações, reveem o que já é conhecido à luz da evidência experimental, usam ferramentas para coletar, analisar e interpretar dados, propõem respostas, explicações e previsões e comunicam os resultados (NATIONAL ACADEMY OF SCIENCES, 1995). A abordagem baseada no inquérito enfatiza como é que aprendemos as coisas em vez de apenas as aprendermos. Em vez de apenas memorizar factos, os alunos e alunas estão ativamente envolvidos na aprendizagem, por isso, aprender torna-se divertido porque os alunos e alunas estão fascinados por algo e isso reflete-se nos seus interesses, objetivos e experiências. O foco 
principal do ensino baseado em inquérito é o Modelo dos 5-E: Envolver, Explorar, Explicar, Elaborar e Avaliar (Evaluation) (BASS; CONTANT; CARIN, 2008).

Métodos experienciais. Baseados na experiencia empírica, enfatizam o papel da experiência prática e da experiência pessoal na construção do conhecimento. No modelo de aprendizagem experiencial de Lewin referido em Kolb (2015), o processo começa com experiências pessoais concretas. A partir dessas experiências, os indivíduos fazem observações e refletem sobre essas observações, constroem conceitos abstratos e generalizações com base nas suas observações e interpretações e podem, então, testar esses conceitos e generalizações em situações novas.

O role-playing (SHANKAR, 2008; HALSTEAD; REISS, 2003) é um desses métodos de aprendizagem, pois permite que os alunos e alunas apliquem o conteúdo que conhecem imediatamente, uma vez que são colocados no papel de um personagem que deve tomar uma decisão sobre uma política, uma decisão pessoal ou alguma outra situação-problema. Este método é excelente para envolver os alunos e alunas e permitir-lhes interagir com os seus pares enquanto tentam desempenhar o papel específico que lhes foi atribuído. Inicialmente é oferecido um cenário relevante aos estudantes. Este cenário deve incluir o papel que o aluno ou aluna vai desempenhar e os detalhes informativos relevantes que vão estar na base das decisões que o seu personagem vai tomar. Estes métodos de aprendizagem experiencial são particularmente úteis para o desenvolvimento de habilidades, porque proporcionam aos alunos uma oportunidade de praticar as suas habilidades e refletir sobre a experiência.

A aprendizagem baseada em projetos ( $\mathrm{ABPj})$ é um método construtivista que organiza o processo de aprendizagem em torno de projetos, com base em questões ou problemas desafiadores que envolvem os alunos e alunas na sua planificação, resolução de problemas, tomadas de decisão ou atividades de investigação e dão aos alunos a oportunidade de trabalhar, relativamente autonomamente, durante longos períodos de tempo para realizarem o projeto que culmina em produtos realistas ou apresentações (JONES; RASMUSSEN; MOFFITT, 1997; MCMAY; GRADEL; SCOTT, 2013). Este método envolve os alunos e alunas num processo de resolução de problemas e incentiva-os/as a trabalharem de forma independente para construir o conhecimento. O processo de aprendizagem pode ter como objetivo a criação de uma exposição, a escrita de uma peça de teatro, a realização de um filme, ensinar os outros dando uma aula, etc., por isso, exige que desde o início da planificação do projeto os alunos e alunas tenham que pensar sobre o produto que irá existir no final do projeto (THOMAS; MERGENDOLLER, 2000). 
A aprendizagem baseada em projetos orientados para a ação (ABPjOA) tem algumas caraterísticas distintivas que a qualificam em relação à $\mathrm{ABPj}$. Em primeiro lugar, nos projetos orientados para a ação os alunos e alunas partem de problemas societais reais e planificam as suas investigações para construir o conhecimento necessário para propor estratégias para a sua resolução, colocando-as em prática. Em segundo lugar, há um conjunto de perspectivas que não representam necessariamente passos que devem ser trabalhados ou seguidos por uma certa ordem, mas questões que devem ser tratadas durante o processo de aprendizagem baseado na investigação dos/as próprios/as participantes (JENSEN, 1994): 1) que assunto deve ser trabalhado; 2) que problema dentro do assunto em questão deve ser trabalhado; 3) quais são as causas deste problema; 4) por que é que se tornou um problema; 5) que alternativas se podem imaginar para o futuro em relação a esse problema (visões para o futuro); 6) quais são os planos de ação que existem para atingir essas alternativas; 7) quais são as barreiras que poderão surgir e impedir que as ações resultem nas mudanças desejadas e como poderão ser ultrapassadas essas barreiras; e 8) que ações serão iniciadas. Nesta fase, os alunos e alunas devem ser criativos para oferecer o maior número de ações possíveis relacionadas com a possibilidade de alcançar algumas das visões previamente desenvolvidas (JENSEN, 2000; SIMOVSKA; JENSEN, 2003, 2009; VILAÇA; JENSEN, 2014). As ações, pensadas e planificadas em função do conhecimento adquirido, podem ser desenvolvidas pelos próprios alunos e alunas ou com a colaboração de quem pedirem (ex., professores/as, pais/mães e especialistas). Para cada ação proposta, os participantes devem discutir as barreiras que podem impedir que essa ação resulte nas mudanças desejadas no estilo de vida e/ou nas condições de vida. Em síntese, o modelo IVAM (investigação, visão, ação e mudança) agora descrito visa medir competências abrangentes dos alunos e alunas (conhecimento e insights, visões, compromisso com o projeto, ações desenvolvidas), em vez de concentrar-se exclusivamente nas suas mudanças no comportamento (SIMOVSKA; JENSEN, 2003; VILAÇA; JENSEN, 2014; VILAÇA, 2017).

\section{Metodologia}

Descrição geral do estudo. Tendo em atenção os objetivos da investigação optou-se por um estudo qualitativo, com recolha de dados através de uma entrevista semiestruturada, sobre as percepções dos professores e professoras acerca da realidade vivida nas escolas do distrito de Braga em relação às metodologias de ensino que estavam a ser aplicadas na educação em sexualidade. O distrito é a estrutura da divisão administrativa em Portugal continental, tendo o 
país 18 distritos, divididos, por sua vez, em municípios ou concelhos que se dividem em freguesias. O distrito de Braga tem 14 municípios onde se encontram 58 Agrupamentos de Escolas. Cada agrupamento de escolas é constituído por um conjunto de escolas que pode integrar estabelecimentos de ensino do pré-escolar ao ensino secundário. Todos os/as participantes no estudo preencheram uma declaração de consentimento informado, onde a confidencialidade, práticas não enganosas e minimização de possíveis danos foram garantidos. Esses princípios éticos orientaram o processo de investigação e a divulgação dos resultados.

Instrumento de recolha de dados. Optou-se por uma entrevista semiestruturada para possibilitar a colocação de uma série de perguntas estruturadas, seguidas de perguntas mais abertas para obter informação adicional e aprofundar a investigação (GALL; BORG; GALL, 1996; KVALE, 1996). As questões estavam dirigidas para as dimensões temática e para a dinâmica das entrevistas (KVALE, 1996) e foram formuladas de uma maneira coloquial para gerar descrições espontâneas e ricas. Após a validação da entrevista por dois especialistas em educação em sexualidade e com um professor e uma professora com as mesmas caraterísticas da amostra, obteve-se um guião final com três áreas de análise: i) caraterização demográfica e profissional dos/as entrevistados/as; ii) temas /problemas trabalhados nos últimos três anos na educação em sexualidade; iii) métodos e técnicas utilizadas na educação em sexualidade.

Participantes. No total de Agrupamentos de Escolas do Distrito de Braga ( $\mathrm{N}=58)$, foi selecionada uma amostra aleatória representativa (PATTON, 1990) para um intervalo de confiança de $95 \%$ e uma margem de erro de 5\% $(n=51)$. Nestes Agrupamentos foi pedido ao diretor ou diretora para indicar um professor ou professora de acordo com os seguintes critérios de inclusão: i) lecionar entre o $7^{\circ}$ e o $12^{\circ}$ anos; ii) ter implementado, nos últimos três anos, um projeto de educação em sexualidade numa turma e ser o coordenador do projeto, quando o projeto incluiu várias turmas; iii) ter implementado um projeto de educação em sexualidade numa turma; e iv) ter aplicado qualquer tipo de material de educação em sexualidade em qualquer atividade escolar. Do total de possíveis entrevistados/as indicados/as aceitaram participar na entrevista 43 professores e professoras (84\% da amostra selecionada). A caraterização da amostra $(n=43)$ encontra-se na Tabela 1.

A amostra de professores/as que trabalhou em educação em sexualidade nas escolas, nos últimos três anos antes da entrevista, era constituída por 43 entrevistados/as, maioritariamente mulheres (81.4\%), com uma média de idades de 37 anos (amplitude 23 a 53 anos, $\mathrm{DP}=5.9)$. A maior parte tinha mais de 35 anos $(60.6 \%)$ e possuía como grau académico Licenciatura (86.0\%) ou Mestrado (11.7\%), era do quadro de nomeação definitiva $(90,7 \%)$ e 
pertencia ao grupo disciplinar de Ciências (Biologia, Biologia e Geologia, Ciências da Natureza e Ciências Naturais) (69,8\%) e de Educação Moral e Religião Católica (11.6\%).

Tabela 1 - Caracterização dos professores entrevistados $(n=43)$

\begin{tabular}{|c|c|c|c|c|c|c|c|c|c|}
\hline \multirow[t]{2}{*}{ Variável } & & $\mathrm{n}$ & $\mathrm{f}$ & $\%$ & Variável & & $\mathrm{n}$ & $\mathrm{f}$ & $\%$ \\
\hline & \multicolumn{4}{|c|}{ Dados biográficos } & \multicolumn{5}{|c|}{ Qualificação e experiência profissional } \\
\hline \multirow[t]{2}{*}{ Sexo } & Homem & 43 & 8 & 18.6 & Categoria & PQND & 43 & 39 & 90.7 \\
\hline & Mulher & & 35 & 81.4 & Profissional & PQZP & & 3 & 7.0 \\
\hline Idade & $20-25$ & 33 & 1 & 3.0 & & Contratado & & 1 & 2.3 \\
\hline$M=37$ & $26-30$ & & 5 & 15.2 & Grupo & Ciências & 43 & 30 & 69.8 \\
\hline $\operatorname{Max}=53$ & $31-35$ & & 7 & 21.2 & disciplinar & História & & 2 & 4.7 \\
\hline $\operatorname{Min}=23$ & $36-40$ & & 12 & 36.4 & & Ed Moral & & 5 & 11.6 \\
\hline \multirow[t]{3}{*}{$\mathrm{DP}=5,9$} & $41-45$ & & 6 & 18.2 & & Filosofia & & 1 & 2.3 \\
\hline & $46-50$ & & 1 & 3.0 & & Ed.Artíst. & & 1 & 2.3 \\
\hline & $51-55$ & & 1 & 3.0 & & Línguas & & 2 & 4.7 \\
\hline Grau & Bacharel. & 43 & 1 & 2.3 & & Ed.Física & & 1 & 2.3 \\
\hline \multirow[t]{6}{*}{ Académico } & Licenciat. & & 37 & 86.0 & & Geografia & & 1 & 2.3 \\
\hline & Mest./Pós & & 5 & 11.7 & \multicolumn{5}{|c|}{ Últimas atividades de Ed. em Sexualidade } \\
\hline & & & & & Nível de & $3^{\circ}$ Ciclo & 43 & 27 & 62.8 \\
\hline & & & & & ensino & Secund. & & 9 & 20.9 \\
\hline & & & & & & $3^{\circ} \mathrm{Cic} . / \mathrm{Sec}$ & & 5 & 11.6 \\
\hline & & & & & & $2^{\circ} / 3^{\circ} \mathrm{Cic}$ & & 2 & 4.7 \\
\hline
\end{tabular}

Fonte: Autoria própria.

PQND: Professor quadro de nomeação definitiva; PQZP: Professor quadro de zona pedagógica.

As últimas atividades dinamizadas dirigiram-se ao $3^{\circ}$ ciclo (62.8\%), secundário (20.9\%) e em simultâneo $3^{\circ}$ ciclo e secundário (11.6\%) ou $2^{\circ}$ e $3^{\circ}$ ciclos (4.7\%).

Tratamento de dados. As entrevistas foram transcritas na integra e foi feita uma análise de conteúdo, seguindo a metodologia descrita por Patton (1990) e Bardin (2011). Primeiro, fezse a leitura dos resultados recolhidos e identificaram-se e codificaram-se as categorias e subcategorias com base no referencial teórico anteriormente revisto (Quadro 1). 
Quadro 1 - Tipologia das práticas de educação em sexualidade descritas

\begin{tabular}{|l|l|}
\hline Categorias & Caraterísticas \\
\hline Método & $\begin{array}{l}\text { Forma como organiza de maneira lógica e sequencia as diversas técnicas e/ou } \\
\text { atividades para atingir os objetivos. }\end{array}$ \\
\hline Técnicas & Formas como vai trabalhar o método com os alunos para atingir os objetivos. \\
\hline Estratégias & $\begin{array}{l}\text { Ação que vai ser realizada pelos professores e alunos em cada técnica e/ou } \\
\text { atividade para atingir os objetivos. }\end{array}$ \\
\hline
\end{tabular}

Fonte: Autoria própria.

Ao longo da apresentação e discussão dos resultados serão colocados alguns excertos de entrevistas para ilustrar os métodos, técnicas e estratégias de ensino encontrados no estudo.

\section{Apresentação e discussão dos resultados}

Em seguida serão descritos os problemas relacionados com a sexualidade e género que foram identificados como necessidade de formação dos alunos e alunas e o tipo de métodos e estratégias pedagógicas usadas na educação em sexualidade nos últimos três anos pelas professoras e professores entrevistados/as.

\section{Problemas que professores/as queriam ajudar a resolver com a educação em sexualidade}

Os problemas relacionados com a sexualidade e género identificados como necessidades de formação dos alunos e alunas foram agrupados em quatro categorias principais: baixo conhecimento biopsicossexual e histórico sobre a sexualidade e género; esclarecer dúvidas e preocupações sobre o prazer sexual (Tabela 2); falta de competências pessoais e sociais; e necessidade de clarificar atitudes e valores face à sexualidade (Tabela 3 ). 
Tabela 2 - Problemas relacionados com o conhecimento abordados na educação em sexualidade

\begin{tabular}{|c|c|}
\hline $\begin{array}{l}3^{\circ} \text { Cicl. } \\
(n=34)\end{array}$ & $\begin{array}{l}\text { Secund. } \\
(n=14)\end{array}$ \\
\hline f & 1 \\
\hline
\end{tabular}

Baixo conhecimento biopsicossexual e histórico sobre a sexualidade e género

O que é a sexualidade humana.

Desenvolvimento biopsicossexual.

Anatomia e fisiologia do sistema reprodutor.

Identidade sexual (Homo, Hetero e Bissexualidade)

Identidade e estereótipos de género.

Onde e como adquirir contraceptivos.

Contracepção e o planeamento familiar.

Fecundação, gravidez e parto.

Meios de transmissão e de prevenção do VIH/ SIDA e de outras

ISTs

Como colocar o preservativo.

Saber onde fazer o teste para o VIH/ SIDA e para as outras ISTs.

Conhecer as disfunções sexuais e terapias.

Parafilias sexuais (exibicionismo, sadomasoquismo, etc.).

Esclarecer dúvidas e preocupações sobre o prazer sexual

Prazer sexual.

Zonas erógenas.

Posições de coito e práticas sexuais.

Resposta sexual humana.

Comportamentos sexuais no namoro. $\begin{array}{llll}13 & 38.2 & 11 & 78.6\end{array}$

$\begin{array}{llll}31 & 91.2 & 1 & 7.1\end{array}$

$\begin{array}{llll}30 & 88.2 & 7 & 50.0\end{array}$

$\begin{array}{llll}15 & 44.1 & 8 & 57.1\end{array}$

$\begin{array}{llll}6 & 17.6 & 9 & 64.3\end{array}$

$\begin{array}{llll}0 & 0 & 5 & 35.7\end{array}$

$\begin{array}{llll}33 & 97.1 & 14 & 100\end{array}$

$\begin{array}{llll}27 & 79.4 & 11 & 78.6\end{array}$

$\begin{array}{llll}30 & 88.2 & 7 & 50.0\end{array}$

$\begin{array}{llll}28 & 82.4 & 6 & 42.9\end{array}$

$\begin{array}{llll}5 & 14.7 & 2 & 14.3\end{array}$

$\begin{array}{llll}0 & 0 & 5 & 35.7\end{array}$

$\begin{array}{llll}0 & 0 & 1 & 7.1\end{array}$

$\begin{array}{llll}3 & 8.8 & 7 & 50.0\end{array}$

$\begin{array}{llll}2 & 5.9 & 1 & 7.1\end{array}$

$\begin{array}{llll}1 & 2.9 & 1 & 7.1\end{array}$

$\begin{array}{llll}1 & 2.9 & 1 & 7.1\end{array}$

$\begin{array}{llll}5 & 14.7 & 6 & 42.9\end{array}$

Fonte: Autoria própria.

Observou-se que os problemas mais frequentemente abordados no $3^{\circ}$ Ciclo relacionados com o baixo conhecimento dos alunos e alunas, com exceção do desenvolvimento biopsicossexual (91.2\%) estavam centrados no conhecimento biológico, como, por exemplo, a anatomia e fisiologia do sistema reprodutor (88.2\%), contracepção e planeamento familiar (97.1\%), meios de transmissão e de prevenção do VIH/SIDA e de outras infeções sexualmente transmissíveis (ISTs) (88.2\%), fecundação gravidez e parto (79.4\%) e como colocar o 
preservativo (82.4\%). No ensino secundário, os problemas mais abordados foram o que é a sexualidade humana (78.6\%), a identidade e os estereótipos de género $(64.3 \%)$ e, tal como no $3^{\circ}$ ciclo, a contracepção e o planeamento familiar (100\%) e a fecundação, gravidez e parto (78.6\%). Cerca de metade dos professores e professoras do ensino secundário ainda abordou a identidade sexual $(57.1 \%)$, o prazer sexual $(50.0 \%)$ e a anatomia e fisiologia do sistema reprodutor $(50.0 \%)$ e meios de transmissão e prevenção do VIH/ SIDA e outras ISTs (50.0\%). Em síntese, no ensino secundário, embora exista um maior número de escolas a abordar problemas que mobilizam mais o desenvolvimento do pensamento crítico dos alunos/as e de desconstrução de estereótipos sociais relacionados com o género, prazer sexual e identidade sexual, o maior foco continua a ser na falta do conhecimento biológico relacionado com a saúde reprodutiva. Este facto pode explicar-se, em parte, por a maior parte dos/as docentes serem da área disciplinar de Ciências/ Biologia e a sua formação em educação para a saúde ser mais focada nos modelos de mudança de comportamentos de saúde individuais e interpessoais (GLANZ; LEWIS; RIMER, 2002; VILAÇA, 2007) do que na pedagogia social crítica (VILAÇA, 2017). Num estudo semelhante realizado cerca de dez anos antes também em Portugal, no distrito de Braga (VILAÇA, 2008), embora os resultados tivessem sido parecidos, os/as docentes praticamente não referiram a identidade e estereótipos de género.

Outras necessidades de formação dos alunos/as que serviram de ponto de partida para a realização de atividades ou projetos de educação em sexualidade por estes professores/as foram a falta de competências sociais e pessoais e a necessidade de criarem condições para que os alunos/as possam clarificar as suas atitudes e valores em relação à sua própria sexualidade e género e à da sua comunidade (Tabela 3 ).

Tabela 3 - Problemas relacionados com competências, atitudes e valores na educação em sexualidade

\begin{tabular}{lcl}
\hline & $\begin{array}{c}3^{\circ} \text { Ciclo } \\
(\mathrm{n}=34)\end{array}$ & $\begin{array}{c}\text { Secund. } \\
(\mathrm{n}=14)\end{array}$ \\
\cline { 3 - 3 } & $\mathrm{f}$ & $\mathrm{f}$
\end{tabular}

Falta de competências pessoais e sociais

Falar com namorado/a sobre prevenção gravidez/ ISTs.

$\begin{array}{llll}20 & 58.8 & 5 & 35.7\end{array}$

Lidar com a pressão para ter sexo.

$\begin{array}{llll}8 & 23.5 & 6 & 42.9\end{array}$

Falar com pais/mães sobre sexo e problemas das relações amorosas.

$\begin{array}{llll}6 & 17.6 & 5 & 35.7\end{array}$

Aprender como e a quem pedir ajuda.

$24 \quad 70.6 \quad 4 \quad 28.6$ 
Lidar com as consequências de ser sexualmente ativo/a.

Saber o que fazer se ele/a ou um amigo/a sofrer abuso sexual.

Melhorar a comunicação interpessoal.

Desenvolver a autoestima, autoeficácia, autoconceito.

Desenvolver o autorrespeito e respeito pelos/as outros/as.

Identificar e resolver problemas relacionados com o género e a sexualidade em situações simuladas.

Identificar e resolver problemas sociais em contexto real.

Desenvolver o pensamento crítico.

Necessidade de clarificação de atitudes e valores

Esperar para ter sexo só quando forem mais velhos, mas se não esperarem, tomarem a pílula e usarem preservativo.

Abstinência.

Aumentar o comprometimento dos alunos/as para terem

comportamentos sexuais saudáveis.

Diminuir a discriminação como resultado da não aceitação das diferenças físicas, morais, identidade sexual e soropositividade VIH.

Clarificar os valores e atitudes face ao comportamento sexual.

Clarificar a atitude pessoal sobre o aborto.

Conhecer a Lei sobre o aborto.

Clarificar a atitude pessoal sobre a prostituição.

Clarificar a atitude pessoal sobre a pornografia e o erotismo.
$25 \quad 73.5 \quad 11 \quad 78.6$

$\begin{array}{llll}5 & 14.7 & 7 & 50.0\end{array}$

$\begin{array}{llll}2 & 5.9 & 0 & 0\end{array}$

$\begin{array}{llll}15 & 44.1 & 7 & 50.0\end{array}$

$\begin{array}{llll}6 & 17.6 & 7 & 50.0\end{array}$

$\begin{array}{llll}28 & 82.4 & 8 & 57.1\end{array}$

$\begin{array}{llll}7 & 22.6 & 4 & 28.6\end{array}$

$\begin{array}{llll}13 & 38.2 & 5 & 35.7\end{array}$

$\begin{array}{llll}15 & 44.1 & 8 & 57.1\end{array}$

$\begin{array}{llll}26 & 76.5 & 7 & 50.0\end{array}$

$\begin{array}{llll}1 & 2.9 & 3 & 21.4\end{array}$

Fonte: Autoria própria.

Uma grande parte de professores/as do $3^{\circ}$ ciclo teve como objetivos que a educação em sexualidade aumentasse a capacidade de alunos/as para desenvolver o respeito por si próprio/a e pelos outros ou outras (82.4\%), aprender a como pedir ajuda e a quem pedir ajuda quando necessitassem (70.6\%) e falar com o namorado ou namorada sobre prevenção da gravidez e de infeções sexualmente transmissíveis (58.8\%). No ensino secundário, a maior parte dos professores visou que os alunos procurassem desenvolver mais o respeito por si próprios/as e pelos/as outro/asas $(57.1 \%)$ e o pensamento crítico $(57.1 \%)$, soubessem lidar com as consequências de serem sexualmente ativos, nomeadamente, terem comportamentos 
preventivos e de monitorização da sua saúde reprodutiva (50.0\%), melhorassem as suas competências de comunicação interpessoal (50.0\%) e desenvolvessem a sua autoestima, autoeficácia e autoconceito $(50.0 \%)$. No $3^{\circ}$ ciclo, os professores e professoras focaram-se mais do que os do ensino secundário na necessidade de clarificação de atitudes e valores, nomeadamente em 'esperar para ter sexo só quando forem mais velhos, mas se não esperarem, tomarem a pílula e usarem o preservativo' (76.5\% versus $50.0 \%$ ), aumentar o compromisso dos alunos/as para terem comportamentos sexuais saudáveis $(73.5 \%$ versus $78.6 \%)$ e diminuir a discriminação como resultado da não aceitação das diferenças físicas e morais, da identidade sexual e da soropositividade para o VIH (61.8\% versus 50.0\%). Tal como em Vilaça (2008) e em vários estudos realizados nos últimos anos em Portugal (RODRIGUES; VILAÇA, 2013), cerca de dez anos depois os professores/as continuaram a identificar como necessidades maiores nestes dois níveis de ensino o desenvolvimento do respeito e a clarificação de algumas atitudes e valores. A grande diferença é que atualmente um maior número de professores/as procurou que os alunos/as fossem capazes de desenvolver o seu pensamento crítico e identificar e resolver problemas sociais em contexto real.

$\mathrm{Na}$ secção seguinte serão descritos os métodos e estratégias usadas na educação em sexualidade por estes professores e professoras para colmatarem nos seus alunos e alunas as necessidades de formação acima referidas.

\section{Métodos e técnicas pedagógicas usados na educação em sexualidade}

Identificação das concepções e interesses dos/as participantes. A maior parte dos professores e professoras para envolver os alunos e alunas no tema/ problema que iam iniciar, pediram-lhes para que individualmente, ou em grupo, colocassem numa caixa de questões, anonimamente, todas as dúvidas, preocupações ou curiosidades que gostariam de ver resolvidas nas atividades ou projeto de educação em sexualidade (86.0\%) (Tabela 4).

$\mathrm{Na}$ maior parte das situações era entregue uma folha em branco na sala de aula e o professor ou professora, posteriormente, categorizava as questões e ia lhes respondendo à medida que desenvolvia o tema/problema. A descrição seguinte ilustra este levantamento inicial dos interesses dos alunos e alunas do $10^{\circ}$ ano de Biologia e Geologia, feita no bar de uma escola:

Como queríamos elaborar um projeto que estivesse de acordo com os interesses dos alunos, pedimos aos alunos para colocarem uma caixa só com uma abertura no Bar da escola e um cartaz a convidar todos os colegas do $10^{\circ}$ ano a deixarem lá, anonimamente, as dúvidas, curiosidade ou preocupações 
que queriam ver esclarecidas no projeto de educação sexual. (...) Depois guardámos essas perguntas e mais tarde, com o grupo de professores envolvido no projeto, dividimos as questões por temas e elaboramos o projeto em função delas. (Ent. 5).

Tabela 4 - Métodos e técnicas pedagógicas usadas na educação em sexualidade ( $n=43)$

Métodos e técnicas

f $\%$

Identificação dos interesses/ necessidades de formação

Caixa de perguntas anónimas.

$37 \quad 86.0$

Questionário anónimo.

$32 \quad 74.4$

Brainstorming em pequeno grupo.

$27 \quad 62.8$

Brainstorming em turma.

\section{Método expositivo ativo}

Exploração de transparências ou slides em turma.

Visionamento de filmes seguidos de debate.

Assistir a conferências, seminários ou workshops.

Criação pelo professor ou professora de websites, blogues ou Facebook baseados nas perguntas dos alunos e alunas.

\section{Método de discussão}

Estudos de caso.

Debates entre estudantes.

Grupos de estudo para resolução de fichas de trabalho.

Grupos de estudo para análise de anúncios, filmes, telenovelas e programas de TV.

\section{Método de investigação}

Investigação na Biblioteca.

Investigação na Internet.

Investigação nos Centros de Saúde e Farmácias.

Visitas de estudo ao Centro de Saúde.

Métodos baseados na experiência empírica

Jogos de papéis para treinar a assertividade.

Outros jogos de papéis (Role-play).

Aprendizagem orientada para a ação:

Mesas redondas/Workshops/Seminários para pais/mães ou comunidade,

organizados por alunos/as, com alunos/as e especialistas como oradores 
Elaboração e assinatura de contratos para assumir o compromisso de implementar as estratégias de mudança que foram objeto de acordo entre participantes

Educação pelos pares:

Educação de pares através de sessões.

Elaboração de cartazes/folhetos/ autocolante para distribuição.

Escrita de teatros/ filmes temáticos e sua dramatização.

Jogos tradicionais e peddy paper.

Elaboração e implementação de jogos temáticos pelos alunos.

Entrevistas (a pais, colegas).

Fonte: Autoria própria.

Também foi frequente, com o mesmo objetivo, aplicarem um questionário anónimo às turmas $(74.4 \%)$ ou fazerem na primeira aula um brainstorming inicial, em pequenos grupos (62.8\%) ou em turma (41.9\%), com organização por subtemas das ideias levantadas e discussão da abrangência do tema/ problema, mas sem responder às questões ou explicar os tópicos que surgiram. No extrato da entrevista seguinte de uma professora que estava a lecionar o $7^{\circ}$ ano de escolaridade de Ciências, ilustra-se esta última situação:

Escrevi a palavra sexualidade no topo do quadro, em maiúsculas, e pedi aos alunos para me dizerem palavras relacionadas com a sexualidade. [...] Fui organizando essas palavras num mapa de conceitos em função das dimensões da sexualidade [...] biológica, psicológica, ética e social. [...] Disseram: relações sexuais, preservativo, homossexualidade, heterossexualidade, bissexualidade [...], VIH, SIDA, soropositivos, [...] sexo oral, sexo anal, prostitutas. [...] Depois voltei a relembrar este esquema durante as aulas sempre que fui esclarecendo um destes conceitos [...] o mapa de conceitos serviu de fio condutor, de organizador do projeto (Ent. 17).

Uma pequena parte de professores optou por começar por discutir o conceito de sexualidade dos próprios alunos e alunas e pedir-lhes que o comparassem, posteriormente, com o da Organização Mundial de Saúde.

Método expositivo. As principais técnicas usadas no método expositivo pelos professores e professoras foram: visionamento de filmes seguido de debate (88.4\%); exploração de transparências ou slides em diálogo turma (81.4\%); assistir a conferências ou seminários $(72.1 \%)$ e criação pelo professor ou professora de websites, blogues ou Facebook baseados nas perguntas dos alunos e alunas (11.6\%). Para maximizar a compreensão e retenção da informação, a maior parte dos professores e professoras utilizou meios audiovisuais para a RIAEE - Revista Ibero-Americana de Estudos em Educação, Araraquara, v. 14, n. 2, p. 1500-1537, jul., 2019. E-ISSN: $1982-5587$. 
projeção de esquemas, gráficos ou imagens em apresentações em Power Point. Geralmente tiveram a preocupação de utilizar como técnica para envolver os participantes durante essas exposições atribuir aos alunos e alunas a responsabilidade de ouvir ativamente através de várias técnicas: fazendo-lhes questões para clarificarem a exposição; pedindo-lhes para no fim responderem ou fazerem questões sobre o assunto; fazendo o sumário dos conteúdos tratados ou pedindo-lhes para fazerem questões orais aos/às colegas sobre o que acabou de ser estudado. Muitas vezes estas técnicas foram aplicadas em turma e, outras vezes, foram aplicadas em pequenos grupos com exposição final em turma. Vários professores e professoras referiram usar técnicas para envolver os participantes ativamente na visualização dos filmes, tais como tomarem notas para responder a questões inicialmente colocadas que os orientavam durante a observação do filme, completarem fichas de trabalho no fim do filme com base no que observaram ou fazerem pequenos debates nos intervalos em que se ia parando o filme. $\mathrm{O}$ excerto da entrevista que a seguir se apresenta mostra como uma professora do $12^{\circ}$ ano de Biologia utilizou um videograma sobre métodos contraceptivos, com duração de 20 minutos:

Decidi mostrar um filme para esclarecer dúvidas sobre os métodos contraceptivos. Sempre que acabava de falar sobre um método eu parava o filme e questionava os alunos. (...) Geralmente começava por perguntar se tinham dúvidas, depois fazia perguntas para ver se tinham compreendido bem (...) O filme era sobre o preservativo, o método das temperaturas, do calendário, do muco... falava da pílula, da contracepção de emergência (...) do dispositivo intrauterino, dos espermicidas, da vasectomia e da laqueação das trompas! (Ent. 42).

O comportamento convencional no fim da utilização do método expositivo, tal como já tinha acontecido num estudo semelhante cerca de dez anos antes (VILAÇA, 2008), foi reforçar os aspectos mais importantes num período de questões. No entanto, o número de professores/as que referiu técnicas mais ativas para esta fase final foi bastante superior ao que se encontrou no estudo anterior. Entre essas técnicas referiram pedir aos participantes para prepararem questões para o professor/a responder; pedir aos alunos e alunas para reverem os conteúdos em grupo e fazerem perguntas para um teste formativo; pedir para preencherem um pequeno questionário que, algumas vezes era de autoavaliação e, outras vezes, era de reflexão sobre as implicações para eles/as do assunto abordado.

Assistir a conferências, seminários ou workshops orientados por especialistas convidados, geralmente médicos/as, enfermeiros/as, psicólogos/as ou investigadores/as, também foi uma estratégia muito utilizada dentro do método expositivo, tal como já tinha acontecido no estudo realizado cerca de dez anos antes (VILAÇA, 2008). Só muito raramente 
é que estas atividades eram voluntárias. Na maior parte das escolas eram realizadas dentro do horário letivo ou como atividades extracurriculares, mas os alunos e alunas eram quase invariavelmente acompanhados/as por um professor ou professora. Este/a docente ajudava a preparar a sessão com o/a especialista convidado/a e durante a sessão exercia um papel de moderador/a do comportamento irreverente de alguns alunos e alunas. Em alguns casos estas palestras eram sugeridas e organizadas por alunos/as para resolver problemas (ações). Na quase totalidade das palestras as narrativas eram do seguinte tipo:

Os palestrantes costumam pedir-nos previamente as questões dos alunos. (...) Numa aula, os alunos colocam questões e enviamos-lhes para organizar a palestra em função delas. (...). Às vezes usam um vídeo sobre os temas que os alunos referiram nas perguntas... usam PowerPoint para os esclarecer ou simplesmente respondem às perguntas dos alunos. (...) (Ent. 37)

Os especialistas externos são muito comuns, no entanto, apesar do seu conhecimento, podem não ter habilidade para controlar a turma ou motivar alunos/as (HILTON, 2001). Além disso, com assuntos tão sensíveis como acontece na educação em sexualidade, alguns alunos e alunas podem sentir-se intimidados com uma pessoa que não é professor/a, embora outros se possam sentir mais relaxados com alguém externo à escola (VILAÇA, 2007). De acordo com Douglas et al. (2001) as características de um bom especialista externo para jovens incluem ser divertido, aberto, alegre, ter boa disposição e um estilo de ensino sem julgamentos, não didático e participativo. Na sua perspectiva, coincidente com a da maior parte dos/as participantes neste estudo, é importante que tenha competências profissionais e interpessoais para compreender as necessidades das escolas e professores/as e para trabalhar com jovens.

Método de discussão. Os "estudos de caso" com apresentação de dilemas e resolução de problemas foram aplicados por $44.2 \%$ dos professores e professoras investigados/as. Os professores e professoras apresentaram aos alunos e alunas uma narrativa de situações reais ou fictícias, em texto escrito ou filme, com o detalhe necessário para ser possível aos grupos analisarem os problemas envolvidos e apresentarem soluções para a sua resolução. A narrativa seguinte de uma professora do $11^{\circ}$ ano, conta como foram usados pequenos filmes com histórias de vida, sobre situações relacionadas com a sexualidade dos/as adolescentes:

Primeiro mostrei um pequeno filme em que um casal de namorados usou incorretamente o preservativo, houve uma gravidez não planeada e tinham que decidir se iriam recorrer ao aborto, ou não. (...) O próprio vídeo está dividido em várias pequenas histórias para promover a discussão. Sempre que acabava a história questionava: Qual é o problema que tem que ser resolvido? O que provocou o problema? O que pode ser feito para o resolver? Quais as vantagens e inconvenientes 
de cada solução (Ent. 21).

A metodologia seguida pelos professores e professoras que aplicaram estudos de caso foi muito semelhante à descrita no extrato acima, e teve sempre como objetivos desenvolver competências de identificação e resolução de problemas e desenvolver o pensamento crítico dos alunos e alunas. Houve, no entanto, algumas variações que podem ser relevantes nos objetivos que se pretendem atingir com a atividade, nomeadamente quando o mesmo professor ou professora aplicou vários estudos de caso (Gráfico 1).

Gráfico 1 - Estratégias de exploração pedagógica dos estudos de caso

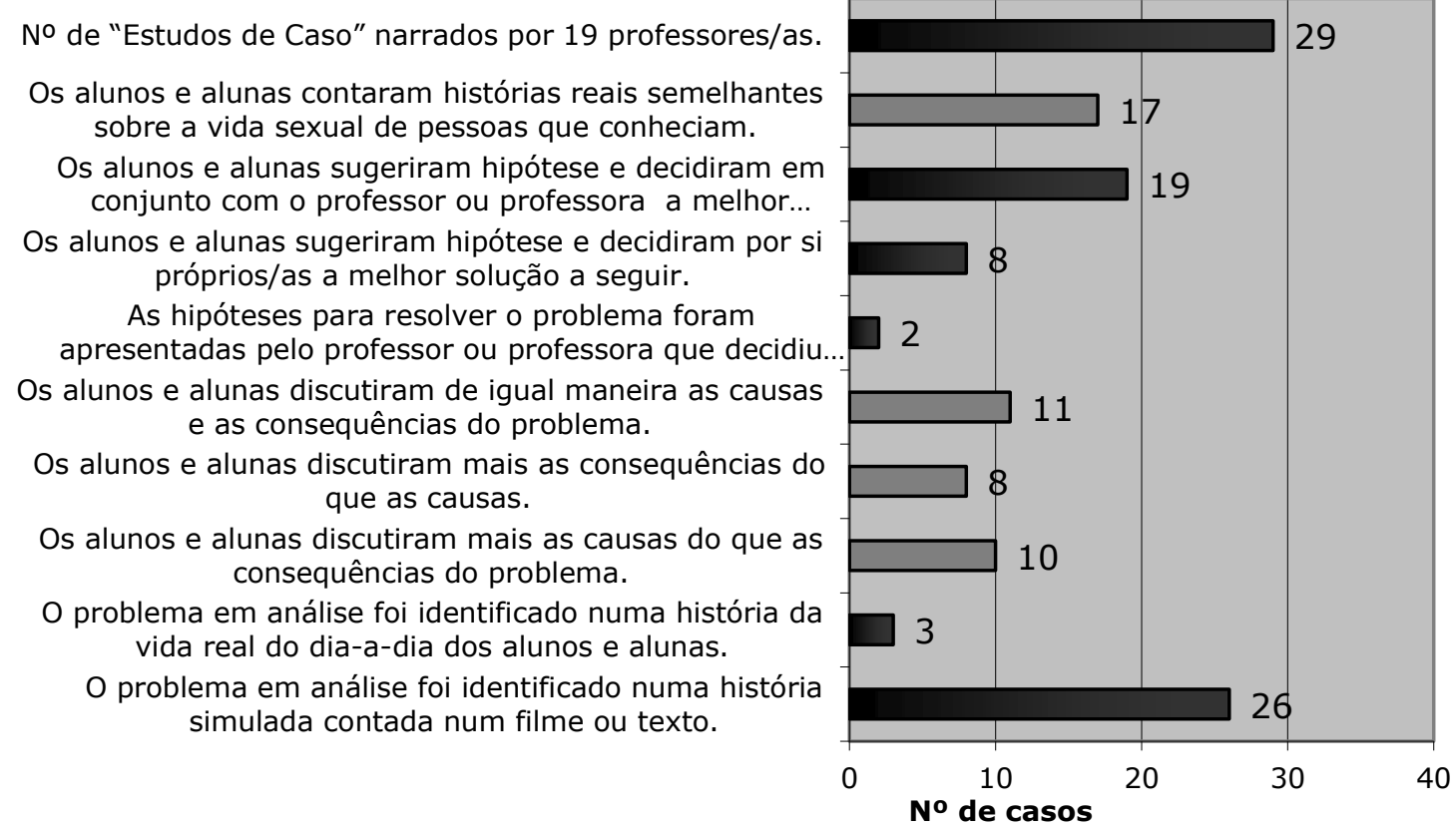

Fonte: Autoria própria.

Em primeiro lugar, o facto do problema em análise ser identificado numa história simulada contada num filme ou texto $(n=26)$ ou numa história da vida real do dia-a-dia dos alunos $(n=3)$ interfere, segundo os professores e professoras, não só na motivação dos alunos e alunas para debaterem qual será a melhor hipótese para resolver o problema e quais teriam sido as causas e consequências do problema, como também pode interferir no facto de sentirem que há maior probabilidade de que o acontecimento descrito lhes possa vir a acontecer. Apesar das vantagens, há uma grande desvantagem que tem que ser equacionada, isto é, discutir casos reais pode levantar problemas graves de juízos de valor que sejam negativos para as pessoas em 
causa. Por essa razão, a maior parte dos professores e professoras, mesmo que já tivesse optado por histórias reais e simuladas para debater, achou mais útil as histórias simuladas.

A construção do conhecimento orientado para a resolução do problema também variou em função dos professores e professoras: dez referiram que neste tipo de atividades os alunos e alunas discutiam mais as causas do que as consequências; oito que discutiam mais as consequências do que as causas do problema e onze que discutiram com a mesma ênfase as causas e as consequências do problema. Vilaça (2014) defende que o conhecimento sobre as consequências dos problemas é importante, porque motiva as pessoas para o tentarem resolver. No entanto, reforça a importância de se trabalhar o conhecimento sobre as causas dos problemas, pois este conhecimento capacita os alunos e alunas para resolverem os problemas nas situações da vida real, agindo sobre elas. Quando comparado com o estudo semelhante realizado cerca de dez anos antes (VILAÇA; 2008), verifica-se que proporcionalmente, atualmente há mais professores e professoras preocupados com a construção do conhecimento sobre as causas dos problemas.

O tipo de participação dos alunos e alunas na sugestão de soluções para resolver o problema e na decisão sobre as melhores soluções, variou desde um nível de baixa participação em que "as hipóteses para resolver o problema foram apresentadas pelo professor ou professora que decidiu com os alunos e alunas quais seriam as melhores soluções" ( $n=2)$, passando por um nível de participação intermédia onde "os alunos e alunas sugeriram as hipóteses para resolver o problema e decidiram por si próprios/as quais seriam as melhores soluções" $(n=8)$, até um nível máximo de participação onde os alunos e alunas sugeriram as soluções e decidiram em conjunto com o professor $(n=11)$. A importância de refletir-se sobre o grau de participação dos alunos e alunas nas várias atividades e projetos educativos tem sido muito valorizada pelos investigadores que trabalham no âmbito das escolas promotoras de saúde em educação para a saúde (SIMOVSKA; JENSEN, 2003; 2009) e educação em sexualidade e gênero (VILAÇA, 2014; 2017), uma vez que aprender a ser participativo não só é uma das competências que tem que ser desenvolvida nos cidadãos de países democráticos para participarem na sociedade, como também é um fator importante na motivação dos alunos e alunas para a aprendizagem.

A maior parte destes professores e professoras $(n=17)$ ainda referiu que posteriormente à exploração das histórias simuladas os alunos e alunas contavam histórias semelhantes da sua vida quotidiana. Isto significa que as histórias foram bem selecionadas pois, tal como é previsto na sua utilização, identificavam-se com a vida real dos alunos e alunas. Para terminar a análise desta técnica de ensino, é interessante refletir sobre o facto da investigação de Hilton (2001) 
mostrar que muitas vezes as "histórias" ou “cenários” estimulam a discussão, mas há diferenças de género na reação à sua implementação, mostrando-se os rapazes menos interessados nelas. Além disso, os estudos de caso construídos a partir das histórias da vida real são uma excelente forma de comunicação, pois, a educação em sexualidade também é uma conversa em que as pessoas aprendem sobre sexo, comportamento sexual e sexualidade através de histórias públicas e privadas contadas em conversas no dia-a-dia, que servem como um espelho para que possam discutir os seus riscos e vulnerabilidades (CASH et al., 2001), prazer e formação de identidades.

A técnica mais usada no método de discussão como alternativo à exposição foi o "grupo de estudo". Os professores referiram frequentemente a utilização de fichas de trabalho (67.4\%) para os alunos resolverem em grupo, clarificando os conteúdos. Um grupo de estudo é um meio excelente para aprender novos conteúdos sem ser por exposição. A análise em grupo de filmes, e a análise de programas informativos da televisão também foram várias opções referidas pelos/as professores/as para o trabalho dos/as alunos/as em grupos de estudo (32.6\%). O extrato da entrevista seguinte descreve a análise de filmes e de programas de televisão num grupo de estudo:

Como já referi na outra vez que me entrevistou, costumo mostrar o filme "Os homens não choram”. Lembra-se? É uma rapariga que não se sente rapariga, sente-se rapaz, arranja uma série de estratégias para ser considerada rapaz até que descobrem e a matam. Os alunos viram o filme, discutiram em grupo e analisaram depois num debate em turma a discriminação dos homossexuais e transgéneros (Ent. 35).

O método geral seguido incluiu dar aos alunos e alunas uma pequena quantidade de material informativo (como o anterior ou, por vezes, notícias de jornais ou revistas, exercícios do livro de Ciências ou pequenas quantidades de informação de outros livros), pedir-lhes para o lerem ou verem em silêncio e formarem grupos de trabalho para estudarem o material seguindo instruções precisas do professor/a do tipo: indicar os conteúdos que foram clarificados; identificar aspectos com que não concordam ou são confusos; arranjar argumentos para o debate final que apoiem as ideias do texto/ filme e que apoiem pontos de vista diferentes; dar exemplos de aplicação desses conhecimentos na sua vida do dia-a-dia e avaliar se compreenderam bem o material. Geralmente o trabalho do grupo foi liderado por um porta-voz que era o representante do grupo nos debates em turma, embora todos os alunos/as acabassem por falar, especialmente quando não se chegava a um consenso.

Método de investigação. Este método foi usado pelos professores geralmente com o 
objetivo final de implementar um debate na turma (88.4\%). Uma das formas mais usadas para os alunos/as procurarem a informação que podia ser ensinada pelo professor/a numa aula expositiva foi dividir os alunos/as em "grupos de investigação" e pedir-lhes para investigarem um tema. Muitas vezes, como os alunos/as tinham pouco conhecimento sobre os temas à priori fizeram uma breve apresentação dos temas para lhes despertar a curiosidade e interesse e estimular a emergência de questões para investigarem. Em muitas situações a turma foi organizada para cada grupo investigar um subtema dentro do tema geral. Os recursos para a investigação foram geralmente sugeridos e decididos pelos alunos/as, que recorreram principalmente à biblioteca da escola (79.1\%), à Internet (67.4\%) e aos Centro de Saúde e farmácias $(20.9 \%)$.

A metodologia que os professores/as seguiram foi em vez de fazerem questões, como nas técnicas anteriores, proporcionarem condições para que os alunos/as fizessem as suas próprias questões para a sua futura compreensão do tópico. Por vezes, houve a organização de um painel de discussão com os porta-vozes dos grupos, moderado pelo professor/a ou por um aluno/a, em que os restantes alunos/as participaram como assistência. No entanto, a maior parte das vezes este debate consistia simplesmente numa apresentação final dos factos, conceitos e opiniões a que cada grupo tinha chegado, apresentados oralmente com a ajuda de transparências ou cartazes, e numa troca de esclarecimentos entre os grupos quando os resultados finais eram diferentes. Este método permite ao professor e professora ensinar de acordo com as necessidades dos/as participantes. Os resultados encontrados para a utilização dos métodos de investigação foram muito semelhantes aos encontrados dez anos antes (VILAÇA, 2008), sendo fundamentalmente centrados na investigação em livros e com recurso à Internet.

Métodos experienciais. $\mathrm{O}$ ensino ativo experiencial promove a aprendizagem "enquanto se faz". As abordagens de aprendizagem baseadas na experiência empírica (aprendizagem experiencial) estão centradas na aprendizagem ativa e são particularmente adequadas para atingir objetivos educativos afetivos e comportamentais, porque ajudam os participantes a tornarem-se mais conscientes sobre os seus sentimentos e reações a certos problemas e a novas ideias (SILBERMAN; LAWSON, 1995; SILBERMAN, 2006). As maiores abordagens da aprendizagem baseada na experiência empírica utilizadas pelos professores e professoras neste estudo foram (Tabela 4, anterior): demonstrações, role playing; e aprendizagem baseada em projetos orientados para a ação.

Geralmente os professores/as ou alunos e alunas na educação pelos pares fazem 
“demonstrações" (67.4\%) dos métodos contraceptivos, especialmente da colocação do preservativo, para os/as outros/as participantes depois treinarem as técnicas apresentadas. Este envolvimento é importante para que possam ver, ouvir e tocar nos materiais de aprendizagem. Em seguida, apresenta-se um desses exemplos num workshop realizado por alunos de $9^{\circ}$ ano para os/ colegas de outras turmas do mesmo ano:

Decidiram ensinar aos colegas como se colocava o preservativo feminino e masculino (...) no feminino usaram um esquema, mostraram como se colocava no esquema e passaram o preservativo de mão em mão (...) Trouxeram uma cenoura, explicaram como se colava o preservativo masculino, distribuíram cenouras e preservativos e pediram aos colegas para treinarem a sua colocação dois a dois. (...) as raparigas procuraram fazer isso com raparigas e notei o mesmo nos rapazes! (..) Trago os vários tipos de pílulas.... o diafragma ... mostro-lhes o DIU colocando-o dentro de uma cânula e depois mostro-lhes o DIU na mão (...) para verem que não magoa, é mole... eles mexem-lhe e veem que é maleável (Ent. 1).

Esta demonstração equaciona, por um lado, a utilização do “erotismo" e da dimensão do prazer sexual para educar, que vários autores (ALLEN, 2001; INGHAM, 2005) têm vindo a referir como um fator de grande importância na educação em sexualidade. Por outro lado, chama a atenção para a possibilidade da utilização de estratégias criativas para contornar as expressões de "machismo" na sala de aula na aprendizagem de assuntos relacionados com a sexualidade.

Os "jogos de papéis (role playing)" foram utilizados por metade dos professores/as $(53.5 \%)$, tendo a sua utilização aumentado consideravelmente em relação ao estudo realizados dez anos antes (VILAÇA, 2008). Tal como no estudo anterior, este método era o que os professores/as conheciam melhor para ajudar os participantes a experimentarem certos sentimentos e a praticarem competências pessoais (e.g. assertividade e a comunicação verbal e não verbal de um modo geral) numa situação simulada. $\mathrm{O}$ role playing é muito aplicado em educação em sexualidade para promover o desenvolvimento de competências sociais e de autorregulação do comportamento e desenvolver a capacidade de recuperação rápida da percepção da autoeficácia (BANDURA, 1986). Nesta investigação as situações de role playing usadas eram semelhantes às reais, descrevendo com precisão as situações de alto risco e as pressões que os/as adolescentes experienciam e integrando a sua história de vida e as suas palavras, frases e sintaxes. Bandura (1989) salienta que mesmo quando as crianças já desenvolveram novas capacidades e estratégias sociais serão necessárias orientações e oportunidades para as aperfeiçoarem, o que é muito bem conseguido em situações de role playing. Na sua opinião, a prática simulada deve ser continuada até que as capacidades sejam 
realizadas profícua e espontaneamente. Esta técnica ajuda os personagens a colocarem-se na pele de outra pessoa. Trata-se de fazer viver uma situação que pode vir a acontecer. É preciso vivenciar a situação simulada não apenas cognitivamente, mas também, com as emoções, sentimentos e as reações corporais que lhe estão associadas.

A "aprendizagem baseada em projetos orientados para a ação" (ABPjOa) foi muito pouco utilizada (Tabela 4, anterior). Quando foi implementada recorreu fundamentalmente à educação pelos pares através de sessões de informação/ sensibilização (32.6\%) e à exposição de cartazes e/ou distribuição de folhetos e autocolantes (30.2\%). Embora a ABPjOa, entendida como a aplicação do modelo IVAM, seja atualmente muito defendida para a educação em sexualidade, tem-se observado que só os professores/as com formação específica nesta abordagem pedagógica a têm aplicado como sucesso (ver por ex., VILACA, 2014, 2017). Apesar disso, observou-se que nas suas formas mais simples o uso desta abordagem aumentou nos últimos dez anos (ver VILAÇA, 2008).

\section{Considerações finais}

Necessidades de formação em educação em sexualidade. Os temas/problemas trabalhados nos últimos três anos na educação em sexualidade nos Agrupamentos de Escolas do distrito de Braga embora mais focados no pensamento crítico e na desconstrução de estereótipos sociais relacionados com o género, prazer sexual e identidade sexual do que no $3^{\circ}$ ciclo, continuaram também a incluir essencialmente a falta de conhecimento biológico sobre saúde reprodutiva. Este facto pode explicar-se, em parte, por a maior parte dos/as docentes serem da área disciplinar de Ciências/Biologia e a sua formação em educação para a saúde ser mais focada nos modelos de mudança de comportamentos de saúde individuais e interpessoais (GLANZ; LEWIS; RIMER, 2002; VILAÇA, 2007) do que na pedagogia social crítica.

A nível do desenvolvimento de atitudes positivas face à sexualidade e competências pessoais e sociais, por um lado, houve semelhanças nos dois níveis de ensino pois a maior parte de professores/as do $3^{\circ}$ ciclo e cerca de $60 \%$ do ensino secundário teve como objetivos que a educação em sexualidade aumentasse a capacidade dos/as alunos/as para desenvolver o respeito por si próprio/a e pelos/as outros/as e a sua competência de comunicação interpessoal, entendida como uma aspeto importante em todos os modelos e teorias de educação para a saúde referidos. Por outro lado, houve preocupações diferentes nos dos níveis de ensino, pois, enquanto no $3^{\circ}$ ciclo se preocuparam mais em criar um rede de suporte social e ensinar os alunos/as a serem 
proativos nessa rede (aspeto essencial na Teoria de Aprendizagem Social e nos Modelo Ecológicos), no ensino secundário houve a preocupação de promoção da saúde reprodutiva acedendo ao Serviço de Saúde para a monitorizar, e de desenvolver a autoestima, autoeficácia e autoconceito dos/as alunos/as a nível da expressão da sua sexualidade e relações interpessoais. Recorde-se que a autorregulação do comportamento, a autoeficácia e a capacidade de recuperação rápida da percepção da autoeficácia são constructos teóricos da Teoria de Aprendizagem Social (BANDURA, 1989).

A nível atitudinal, observou-se que no $3^{\circ}$ ciclo, os/as professores/as focaram-se mais do que os/as do ensino secundário na necessidade de clarificação de atitudes e valores, nomeadamente em 'esperar para ter sexo só quando forem mais velhos, mas se não esperarem, tomarem a pílula e usarem o preservativo', em aumentar o comprometimento dos alunos/as para terem comportamentos sexuais saudáveis e diminuírem a discriminação como resultado da não aceitação das diferenças físicas e morais, da identidade sexual e da soropositividade para o VIH. Estes resultados têm-se encontrado em vários estudos realizados em Portugal nos últimos anos com alunos semelhantes (ex., RODRIGUES; VILAÇA, 2013; VILAÇA, 2011).

Quando se compara este estudo com outro realizado cerca de dez anos antes (VILAÇA, 2008) no mesmo distrito, com uma amostra de conveniência de professores ( $\mathrm{n}=87$ ) com caraterísticas semelhantes, verifica-se que atualmente: i) é semelhante o foco maior na componente biológica da sexualidade; ii) há mais docentes a trabalhar na educação em sexualidade as identidades sexuais e de género; iii) é semelhante considerarem necessidades maiores nestes dois níveis de ensino o desenvolvimento do respeito por si próprio/a e pelos/as outros/as e melhorar a comunicação interpessoal (ex., namorado, pais/mães), assertividade, resistência à pressão e negociar e lidar com conflitos; iv) é semelhante valorizarem mais nos dois níveis de ensino a clarificação de algumas atitudes e valores, nomeadamente, 'esperar para ter sexo só quando forem mais velhos, mas se não esperarem tomarem a pílula e usarem o preservativo', aumentar o compromisso dos/as alunos com os comportamentos sexuais saudáveis, diminuir a discriminação relacionada com a diversidade sexual e valorizarem menos 'falar sobre o prazer sexual', o erotismo, o aborto, a prostituição e a pornografia.

Métodos e técnicas utilizadas na educação em sexualidade. Metodologicamente, os/as professores/as dos dois níveis de ensino usaram pressupostos construtivistas na educação em sexualidade, nomeadamente quase todos/as referiram organizar o seu ensino a partir da identificação dos interesses ou necessidades de formação dos/as alunos/as e identificaram as suas concepções alternativas tentando fazer um ensino a partir delas. Também se observou que 
foram usados essencialmente métodos centrados no/a aluno/a, mais frequentemente a exposição intercalada com métodos de discussão e sessões exclusivamente de discussão utilizando uma sequência de diferentes técnicas que utilizam o questionamento como estratégia facilitadora da aprendizagem ativa, como os grupos de estudo para resolução de fichas de trabalho ou para análise de anúncios, filmes, telenovelas e programas de TV, debates entre estudantes e estudos de caso. Os métodos de investigação foram essencialmente usados como sinónimo de pesquisas na biblioteca e na Internet, tendo-se verificado que a aprendizagem baseada em inquérito apenas emergiu nos projetos de educação em sexualidade orientada para a ação, que aconteceram muito raramente. Também se observou que os métodos experiencias, com exceção do role-playing e das demonstrações seguidas de treino, foram poucas vezes utilizados. $\mathrm{O}$ mesmo aconteceu com a aprendizagem baseada em projetos e a aprendizagem baseada em projetos orientados para a ação de promoção da saúde sexual e equidade de género.

Observou-se que os estudos de caso e o role-playing foram usados como estratégias estandardizadas para a resolução de problemas que partiram geralmente de situações-problema selecionadas pelo/a professor/a. Os objetivos que os/as professores/as associaram à sua implementação foram o desenvolvimento de competências de comunicação (assertividade, argumentação e co-argumentação e autoeficácia) e a capacidade de identificar problemas, compreender as suas consequências e causas e propor estratégias para a sua resolução, desenvolvendo apenas subcompetências de baixo nível desenvolvidas em relativo isolamento, tal como já tinha acontecido dez anos antes (VILAÇA, 2008). Como observado noutros estudos, verificou-se que nesta investigação poucos recursos foram dedicados a atividades de resolução de problemas de ordem superior, como a aprendizagem baseada em problemas, a aprendizagem baseada em projetos e a aprendizagem baseada em projetos orientados para a ação, que exigem que os/as alunos/as integrem e (re)construam e/ou apliquem conhecimento conceitual e desenvolvam adequadamente subcompetências de resolução de problemas em trabalho cooperativo (VILAÇA, 2015).

O cruzamento dos temas e metodologia utilizados permitiu inferir que a maior parte dos professores/as não usava um referencial teórico explícito, mas valorizava constructos da Teoria Social Cognitiva e Modelo Ecológico. Quando se compara este estudo com o outro realizado cerca de dez anos antes (VILAÇA, 2008), verifica-se que: i) há uma maior preocupação com a identificação dos interesses e necessidades de formação dos/as alunos/as; ii) continuam a ser usados preferencialmente os métodos expositivos ativos e o método de discussão; iii) na exposição dos conteúdos foram referidas as mesmas técnicas e há a mesma preocupação em 
usar técnicas para ganhar o interesse dos/as alunos/as, maximizar a compreensão e retenção da informação e os pressupostos construtivistas, envolver os participantes ativamente durante a exposição e reforçar a exposição (embora nesta última fase atualmente os professores tenham referido técnicas mais ativas); iv) utilizaram as mesmas técnicas no método de discussão, mas nos estudos de caso observou-se uma maior preocupação com a construção do conhecimento orientado para a ação, uma maior preocupação com o conhecimento interdisciplinar sobre as causas do problema e com um grau de participação maior dos/as alunos/as; v) a nível dos métodos experienciais, atualmente, embora ainda pouco utilizados, houve um acréscimo na utilização do role-playing e da metodologia IVAM que resultou em ações de educação pelos pares para a resolução do problema inicialmente identificado.

Em suma, as percepções destes/as professores/as sobre as suas práticas de educação em sexualidade, nos últimos três anos, desafiam os/as formadores/as de professores/as a integrar na dinâmica da formação contínua e desenvolvimento profissional de professores/as em educação em sexualidade:

i) o aprofundamento científico dos conteúdos disciplinares e interdisciplinares relacionados com a sexualidade humana, numa perspectiva inclusiva (integrar o desenvolvimento sexual de crianças e adolescentes com diferentes deficiências e sem deficiência);

ii) um posicionamento crítico dos/as participantes sobre as teorias e modelos de educação para a saúde e sexualidade orientados para as mudanças de comportamento individuais (como o Modelo de Crenças de Saúde, Teoria da Ação Racional e Comportamento Planeado, Modelo Transteórico), interpessoais (como a Teoria Social Cognitiva e os Modelos Ecológicos) e de mudança de estilos de vida e condições de vida (como o modelo de aprendizagem IVAM, enquadrado no Paradigma de Educação para a Saúde Democrática e na teoria social crítica);

ii) a análise das relações entre os referenciais teóricos de educação em sexualidade e os métodos, técnicas e estratégias de ensino construtivistas;

iii) a análise de experiências de intervenção e investigação em educação em sexualidade; iv) o desenvolvimento de competências reflexivas face ao exercício das funções de educador/a sexual e à formação profissional nesta área;

v) o desenvolvimento de competências de regulação de processos de (auto)supervisão na educação em sexualidade que contribuam para a melhoria sustentada da prática. 


\section{REFERÊNCIAS}

ALLEN, L. Closing sex education's knowledge/practice gap: the reconceptualisation of young people's sexual knowledge. Sex education, Oxford, v. 1, n. 2, p. 109-122, 2001.

BANDURA, A. Social Foundations of thought and action: A social cognitive theory. New Jersey: Prentice-Hall. 1986.

BARDIN, L. Análise de conteúdo. Lisboa: Edições 70, 2011.

BASS, J. E.; CONTANT, T. L.; CARIN, A. A. Methods for teaching science as inquiry (10th ed.). Upper Saddle River, NJ: Pearson Prentice Hall. 2008.

BISHOP, A. P.; BERTRAM, B. C.; LUNSFORD, K. J. et al. Supporting Community Inquiry with Digital Resources. Journal of Digital Information, Illinois, v. 5, n. 3, p. 2004.

BREWER T.; RIMER, K. Health behavior theories that focus on individuals. In: GLANZ, K.; RIMER, K.; VISWANATH, K. (Org.). Health Behavior and Health Education: Theory, Research and Practice. 4 ed. San Francisco: Jossey-Bass Pub. p. 149-165, 2008.

BROOKFIELD, S. D.; STEPHEN, P. Discussion as a Way of Teaching: Tools and Techniques for Democratic Classrooms, 2. ed. San Francisco: Jossey-Bass, 2005.

CASH, K.; KHAN, S. I.; NASREEN, H.; BHUIYA, A.; CHOWDHURY, S.; CHODHURY, M. R. Telling them their own stories: legitimizing sexual and reproductive health education in rural Bangladesh. Sex education, Oxford, v. 1, n. 1, p. 43-57, 2001.

DOUGLAS, N.; KEMP, S.; AGGLETON, P.; WARWICK, I. The role of external professionals in Education about sexual orientation - towards good practice. Sex education, Oxford, v. 1, n. 2, p. 149-162, 2001.

FREIMUTH, V. S. Theoretical foundations of AIDS Media Campaigns. In: EDGAR, T.; FITZPATRICK, M. A.; FREIMUTH, V. S. (Eds.). AIDS: A Communication Perspective. New Jersey: Lawrence Erlbaum Associates, p. 91-110, 1992.

GALL, M. D.; BORG, W. R.; GALL, J. P. Educational research: An introduction. London: Longman Publishers. 1996.

GLANZ, K.; LEWIS, F. M.; RIMER, B. K. Health Behavior and Health Education: Theory, Research and Practice,3. ed. San Francisco: Jossey-Bass Publishers. 2002.

GLANZ, K.; RIMER, B. K.; VISWANATH, K., Health Behavior and Health Education: Theory, Research and Practice, 4. ed. San Francisco: Jossey-Bass Publishers. 2008.

HALSTEAD, J. M.; REISS, M. J. Values in Sex Education: From principles to practice. London and New York: Routledg Falmer, Taylor \& Francis Group. 2003.

HILTON, G. L. S. Sex education: the issues when working with boys. Sex Education, Oxford, v. 1, n. 1, p. 31-41, 2001. 
HINGHAM, R. 'We didn't cover that at school': education against pleasure or education for pleasure? Sex education, Oxford, v. 5, n. 4, p. 375-388, 2005.

JENSEN B. B. Participation, commitment and knowledge as components of pupil's action competence. In: JENSEN, B. B.; SCHNACK, K.; SIMOVSKA, V. (Org.). Critical environmental and health education. Copenhagen: Research Centre for Environmental and Health Education, p. 219-237, 2000.

JENSEN, B. B. Health promoting schools in Denmark: an action competence approach to health education. In: CHU, C.; SIMPSON, K. R. (Org.). Ecological public health: from vision to practice. Canada: Institute of Applied Environmental Research, p.132-141, 1994.

JENSEN, B. B. A case of two paradigms within health education. Health Education Research, Oxford, v. 12, n. 4, p. 419-428, 1997.

JENSEN, B. B.; SCHNACK, K. Action competence as an educational challenge. In: JENSEN, B. B.; SCHNACK, K. (Org.). Action and action competence as key concepts in critical pedagogy. Copenhagen: Didaktiske Studier, p. 5-18, 1994.

JONES, B. F.; RASMUSSEN, C. M.; MOFFITT, M. C. Real-life problem solving: A collaborative approach to interdisciplinary learning. Washington DC: American Psychological Association. 1997.

JOYCE, B.; WEIL, M. Models of Teaching. Boston: Allyn \& Bacon, 1996.

KIRSCHT, J. P.; JOSEPH, U. G. The health belief model: Some implications for behavior change with reference to homossexual males. In: MAYS, V.; ALBEE, G.W.; SCHNEIDER, S.F. (Eds.). Primary Prevention of AIDS: Psychological Approaches. Newbury Park: Sage, p. 111-127, 1989.

KOLB, D. A. Experiential learning: Experience as the source of learning and development (2nd. Edition). Saddle River, New Jersey: Pearson Edication, Inc. 2015.

KVALE, S. InterViews: an introduction to qualitative research interviewing. London: Sage Publications. 1996.

LÓPEZ, F.; FUERTES, A. Para Comprender La Sexualidad. Navarra: Editorial Verbo Divino. 1999.

MCALISTER, A. L.; PERRY, C. L.; PARCEL, G. S. How Individuals, environments, and Health behaviors interact. Social Cognitive Theory. In: GLANZ, K.; RIMER, B. K.; VISWANATH, K. (Org.). Health Behavior and Health Education: Theory, Research and Practice, 4. ed. San Francisco: Jossey-Bass Publishers, p. 169-188, 2008.

NATIONAL COMMITTEE ON SCIENCE EDUCATION STANDARDS AND ASSESSMENT, NATIONAL RESEARCH COUNCIL. National Science Education Standards. Washington, D.C.: National Academies Press. 1995.

PARSON, C.; STEARS, D.; THOMAS, C. United Kingdom - The eco-holistic model of the Health Promoting School. In: Jensen, B.B.; Simovska V. (Ed.). Models of promoting health RIAEE - Revista Ibero-Americana de Estudos em Educação, Araraquara, v. 14, n. 2, p. 1500-1537, jul., 2019. E-ISSN: 1982-5587. DOI: 10.21723 /riaee.v14iesp.2.12614 
schools in Europe. Copenhagen: EENHPS, WHO Regional Office for Europe, p. 64-66, 2002.

PATTON, M. Q. Qualitative evaluation and research methods. London: Sage Pub. 1990.

RODRIGUES, C. DE J.; VILAÇA, T. Educação em Sexualidade na Educação Moral e Religiosa Católica no $7^{\circ}$ ano de escolaridade em Portugal. Revista Ibero-Americana de Estudos em Educação, Universidade Estadual Paulista Faculdade de Ciências e Letras Araraquara, SP, v. 8, n. 3, p. 561-576, 2013.

SALLIS, F.; OWEN, N.; FISHER, B. Elological models of health behavior. In: GLANZ, K.; RIMER, K.; VISWANATH, K. (Org.). Health Behavior and Health Education: Theory, Research and Practice, 4. ed. San Francisco: Jossey-Bass Pub, p. 465-485, 2008.

SÁNCHEZ, F. L. La inocência rota: Abusos sexuales a menores. Barcelona: Oceano Grupo Editorial, S.A. 1999.

SÁNCHEZ, F. L. Modelos de intervenção em educação sexual. Comunicação apresentada no Seminário Educação Sexual nas Escolas - Desafios e responsabilidades, 14-16 Novembro 2002 na Associação para o Planeamento da Família (não publicada). 2002.

SHANKAR, P. R., Using Case Scenarios and Role Plays to Explore Issues of Human Sexuality. Education for Health, Wolters Kluer, India, v. 20, n. 3, p 1-5, 2008.

SILBERMAN, M. Active Training. A Handbook of techniques, Designs, and Tips, 3. ed. USA: Jossey-Bass/ Pfeiffer. 2006.

SILBERMAN, M.; AUERBACH, C. 101 Ways to make training active. USA: Jossey-Bass/ Pfeiffer. 1998.

SIMOVSKA, V.; JENSEN, B. B. Young-minds.net/lessons learnt: student participation, action and cross-cultural collaboration in a virtual classroom. Copenhagen: Danish University of Education Press, 2003.

SIMOVSKA, V.; JENSEN, B. B. Conceptualizing participation: the health of children and young people. Copenhagen: World Health Organization Regional Office for Europe, 2009.

SVINIVKI, M.; MCKEACHIE, W., et al. McKeachie's Teaching Tips: Strategies, Research, and Theory for College and University Teachers, 13. ed. Belmont, USA: Wadsworth, Cengage Learning, 2011.

THARP, R. G.; GALLIMORE, R. Rousing minds to life: Teaching, learning, and schooling in social context. Cambridge: Cambridge University Press. 1988.

THOMAS, J. W.; MERGENDOLLER, J. R. Managing project-based learning: Principles from the field. Paper presented at the Annual Meeting of the American Educational Research Association, New Orleans. 2000.

VIGOTSKY, L. S. A construção do pensamento e da linguagem. São Paulo: Martins Fontes, 2000. 
VILAÇA, T. Dos Modelos de Educação para a Saúde Tradicionais aos Modelos de Capacitação: Abordagens Metodológicas da Educação Sexual em Portugal do $7^{\circ}$ ao $12^{\circ}$ anos de Escolaridade. In: ENCIGA (Eds.). Actas do XX Congreso Associación dos Ensinantes de Ciências de Galicia. Sanxenxo: ENCIGA, p. 1-30, 2007.

VILAÇA, T. Development Dynamics of Action-Oriented Learning on Health Education. In: MUÑOZ M.; JELÍNEK I.; F. FERREIRA, (Org.). Proceedings of the IASK International Conference Teaching and Learning 2008. Aveiro: IASK- International Association for the Scientific Knowledge; Universidade de Aveiro, p. 74-83, 2008.

VILAÇA, T. Projecto de Educação sexual orientado para a ação e participação: efeitos nas escolas, professores, pais e alunos. In: CONGRESSO INTERNACIONAL SA.DE, CULTURA E SOCIEDADE, 3, 2008, Portalegre. Anais... Portalegre: Associação para a Investigação e Desenvolvimento Sócio-Cultural, p. 128-159, 2008.

VILAÇA, T. Percepções de professores/as sobre as diferenças de género na educação em sexualidade em escolas portuguesas. Educação: Teoria e Prática, Rio Claro - SP/ Brasil, v. 24, n. 45, p. $23-39,2014$

VILAÇA, T. A multiple case study based on action-oriented sexuality education: Perspectives of Portuguese teachers. Health Education, SAGE Publishing - United Kingdom, v. 117, n. 1, p. 110-126, 2017.

VILAÇA, T; JENSEN, B. B. Applying the S-IVAC methodology in schools to explore students creativity to solve sexual health problems. In: MONTAN., M.; SALAZAR, J. (Org.). ATEE 2009 Annual Conference Proceedings. Brussels: ATEE Association for Teacher Education in Europe, p. 215-227, 2010

VILAÇA, T.; JENSEN, B. B. Aplicando a metodologia S - IVAC em escolas para explorar a criatividade dos alunos em resolver problemas de saúde sexual. Educação: Teoria e Prática, Rio Claro, v. 24, n. 45, p. 216-232, 2014.

WEARE, K. The health promoting school: an overview of concept, principles and strategies and the evidence for their effectiveness. In: EC; WHO EUROPE et al. (Ed.). First Workshop on Practice of Evaluation of the Health Promoting School: Models, experiences and perspectives. Switzerland: WHO EUROPE, p. 9-18, 1998.

\section{Como referenciar este artigo}

VILAÇA, Teresa. Metodologias de ensino na educação em sexualidade: desafios para a formação contínua. Revista Ibero-Americana de Estudos em Educação, Araraquara, v. 14, n. 2, p. 1500-1537, jul., 2019. E-ISSN: 1982-5587. DOI: 10.21723/riaee.v14iesp.2.12614

Submetido em: 30/09/2018

Revisões requeridas: 20/02/2019

Aprovado em: 30/04/2019

Publicado em: 25/06/2019 
